\title{
Complex Heat Pump Operational Mode Identification and Comparison for Use in Electric Vehicles
}

\author{
James Jeffs *, Andrew McGordon, Alessandro Picarelli, Simon Robinson, Yashraj Tripathy and \\ Widanalage Dhammika Widanage
}

WMG, University of Warwick, Coventry CV4 7AL, UK; A.McGordon@warwick.ac.uk (A.M.); alessandro.picarelli@claytex.com (A.P.); srobin43@jaguarlandrover.com (S.R.); Y.Tripathy@warwick.ac.uk (Y.T.); Dhammika.Widanalage@warwick.ac.uk (W.D.W.)

* Correspondence: J.Jeffs@Warwick.ac.uk

Received: 10 July 2018; Accepted: 24 July 2018; Published: 1 August 2018

\begin{abstract}
Previous research has focused on the use of heat pumps in electric vehicles, with the focus on recuperating heat from, normally, ambient and one thermal source on the vehicle. Here 5 potential thermal sources on a vehicle have been identified and thorough testing on the benefit of each source has been performed. The results presented suggest the motor, a thermal storage device, and cabin exhaust extraction should be used $>80 \%$ of the time according to the scenarios tested, while battery heating and transmission heat extraction should be used subject to conditions on the ambient temperature and drive cycle.
\end{abstract}

Keywords: electric vehicles; heat pumps; energy flow; heat; energy storage

\section{Introduction}

Hybrid and electric vehicles, as part of low carbon personal transport, are growing in demand as a result of rising atmospheric carbon dioxide levels [1] and increased emissions regulations. One concern for owners of electric vehicles is the range depletion that they experience during the winter months [2-4]. Conventional internal combustion engine vehicles are able to supply the cabin with acceptable heat generated by an inefficient combustion engine for comfortable cabin heating [5]. Electric vehicles are much more efficient, producing less waste heat, and so have traditionally used positive thermal coefficient (PTC) heaters to warm the cabin [6]. These use energy from the battery and so reduce the vehicle's range. Electric only range can be reduced by as much as $60 \%$ when the ambient temperature drops to $-20^{\circ} \mathrm{C}$ compared to $20^{\circ} \mathrm{C}$ [7]. This is due to the combined effect of reduced battery performance and the increased demand on the battery to provide heat to the cabin $[7,8]$. Hybrid electric vehicles have the option to use their combustion engine in cold climates to increase cabin heating capacity. Since electric only vehicles do not have this option, the way in which they generate heat is more important to their range, hence focus be put on electric only vehicles opposed to hybrid electric vehicles.

\subsection{Low Temperature Issues with EVs}

Electric batteries have reduced performance when operating below $0{ }^{\circ} \mathrm{C}$. Many investigations have been carried out on the capacity reduction of Lithium ion batteries in cold temperatures with results ranging between $20-40 \%$ capacity decrease at $-20{ }^{\circ} \mathrm{C}$ [9-12]; this directly leads to $20-40 \%$ reduction in range. Cell manufacturers also publish capacity as a function of temperature on data sheets for their cells; Panasonic published a coulombic capacity reduction of approximately $35 \%$ using a discharge rate of $0.5 \mathrm{C}$ (where $\mathrm{C}$ is defined as the current required to discharge a cell by $100 \%$ in $1 \mathrm{~h}$ ) when operating at $-20^{\circ} \mathrm{C}[13]$. 
At low temperatures, cells are also affected by reduced power capability $[14,15]$ and increased ageing while charging [16,17]. The literature concerning reduction in power capability has mainly focused on chemistries more suited to hybrid vehicles, e.g., Lithium Iron Phosphate. Rui [14], Zheng [15] and Jaguemont [18] concluded that the primary cause of power capability reduction was due to an increase in charge transfer resistance. This is a result of slow/sluggish electrolyte kinetics caused by low temperature [18]. In 2016 Zheng et al. showed a power capability reduction by approximately $90 \%$ when lowering the ambient temperature from $20^{\circ} \mathrm{C}$ to $-20{ }^{\circ} \mathrm{C}$. In the context of hybrids this leads to concerns over whether on a cold day the on-board battery would be able to supply enough power to crank the engine, a serious concern for vehicles with only one lithium ion battery for operation. However there is little evidence to suggest that power would be a problem in EVs. EVs operate at a lower $C$ rate than HEVs $[19,20]$ and so are less affected by reductions in power capability. This is further explained in a report by Saxena et al., where in proposing updated end of life criteria for batteries they highlight cases where $30 \%$ of remaining power capability is able to meet the power requirements of 3 drive cycles (UDDS, HWFET, US06) [21]. This means that if cold temperature power limitation were to affect the vehicle it would only be a problem when demanding the vehicle's maximum power. If the rest of the vehicle is at $-20{ }^{\circ} \mathrm{C}$ then it is unlikely that this power could be delivered to the road. This would explain why there seems to be little concern over power reduction of EVs in cold climates.

The primary non-powertrain battery load during cold climate driving is cabin heating demand [22,23]. Traditionally this heat has been produced using positive thermal coefficient (PTC) heaters, which have a typical efficiency of $\approx 95 \%$ [24]. In a conventional vehicle, where approximately two thirds of on-board energy is wasted, cabin heating is not a problem [25]. In comparison, an electric vehicle is approximately $80 \%$ efficient at using its on-board energy for driving, which means much less waste heat is available [26,27]. Hence heating will lead to an extra load on the battery and reduce the range. Broglia et al. used a system simulation approach to show that at $-5^{\circ} \mathrm{C}$ heating and battery inefficiency could lead to a $33 \%$ increase in energy consumption [23]. Meyer et al. investigated the split between cabin heating and low temperature battery effects, performing tests with heating on full (continuously) and heating off at $-7{ }^{\circ} \mathrm{C}$. During the two tests at $-7^{\circ} \mathrm{C}$ over the LA4 drive cycle (also known as FTP-72 or the Urban Dynamometer Driving Schedule), Meyer et al. found that the use of PTC heaters led to a $41 \%$ reduction in vehicle range compared to its $20{ }^{\circ} \mathrm{C}$ range. In comparison, a range reduction of just $15 \%$ was found with the heating off at the same temperature [7], which can be attributed to the effect of low temperatures on an Li-ion battery. The combined effect of heating demand and reduced battery capacity is a $60 \%$ reduction in range at $-20^{\circ} \mathrm{C}[7,8]$. One result of this range reduction at low temperatures is an increase in research into more efficient heating solutions for electric vehicles.

\subsection{Potential Solutions}

One way to reduce the energy demand of heating is to use a heat pump instead of PTC heaters. Heat pumps utilise the available waste heat and extract some thermal energy from ambient. Leighton et al. and Ahn et al. have shown the prospective benefits, providing ambient conditions are suitable, of using heat pumps in electric vehicles [28,29]. Leighton showed that a system that could utilise waste heat from the inverter and electric motor could provide a $2.6 \%$ improvement in range at $-12{ }^{\circ} \mathrm{C}$, taking the low temperature range from $46.2 \%$ to $48.8 \%$ of the nominal range. The improvement was even larger at more moderate temperatures, at $13{ }^{\circ} \mathrm{C}$ the range was increased from $66.6 \%$ to $82.1 \%$ of the nominal range, a $15.5 \%$ improvement. The system tested by Leighton et al. was able to heat the cabin air from $-2{ }^{\circ} \mathrm{C}$ to $22{ }^{\circ} \mathrm{C}$, in approximately $23 \mathrm{~min}$; which is an important metric to consider when evaluating the performance of a heating system. Leighton did not discuss their system's coefficient of performance (COP). COP is a unit-less measure of the performance of a system and is defined for a heat pump in Equation (1), where $P_{\text {compressor }}$ is compressor power and $Q_{\text {condenser }}$ is the heat extracted from the condenser. Ahn et al. tested characterised the performance of a dual source (ambient and motor) heat pump, investigating the impact of providing additional heat to the system. In their findings it was shown that as the motor waste heat was increased from $0 \mathrm{~kW}$ to $2.5 \mathrm{~kW}$ the heat pump COP increased 
from 3.2 to 3.4. Ahn et al. also compared motor and ambient as single sources to the heat pump, here they achieved COPs of 3.1 and 3.2 respectively. This shows that supplying more waste heat to a heat pump results in better performance.

$$
\text { COP }=\frac{Q_{\text {condenser }}}{P_{\text {compressor }}}
$$

Currently the use of heat pumps is hindered by their slow warm up times and they require additional PTC heaters for fast response [6].

The use of thermal batteries, which are constructed from a phase change material (PCM), have been suggested for use in the automotive context by a selection of researchers [30,31]. Shahidinejad et al. was able to achieve a $21 \%$ vehicle level energy saving during the warm up period [30]. This was achieved in simulation using average driving data from Winnipeg, where the average speed and distance of a commute was $32.5 \mathrm{kmh}^{-1}$ and $32.7 \mathrm{~km}$ respectively, the average monthly temperature ranged between $-13.6^{\circ} \mathrm{C}$ and $-17.8^{\circ} \mathrm{C}$ during the winter months, although the temperature simulated was not specified.

In $2016 \mathrm{LaClair}$ et al. proposed the use of a $2.7 \mathrm{kWh}$ thermal battery weighing $33 \mathrm{~kg}$ with a volume of $31 \mathrm{~L}$ to cover the entire heating load for a $23 \mathrm{~min}$ commute twice in a day (46 min total) [32]. The thermal battery had an operating temperature range of 60 to $120^{\circ} \mathrm{C}$, where $60^{\circ} \mathrm{C}$ was deemed the minimum temperature useful for cabin heating. LaClair et al. assumed an electrical battery with capacity $10 \mathrm{kWh}$ and average heating requirement of $3.13 \mathrm{~kW}$. Assuming this heating demand can now be catered for by the thermal battery, they concluded that adding the thermal battery increased the electrical energy available for traction by $38 \%$.

Kaygusuz proved the benefits of using a thermal battery to manage solar energy in a heat pump heated house [33]. Here the ability to manage thermal energy meant that the heat pump could be operated at a COP of up to 4.7, compared to COP of 3 without the thermal storage. The application of thermal storage could be integrated into a vehicle, this could be charged using the on-board PTC heater when the electric battery charge is complete, negating the need for solar panels. This would provide and additional, fast response heat source with the potential to replace the PTC heater. The integration of a thermal storage system was explored further by Jeffs et al. in [34]. Here the sizing of such a device was considered and the performance improvement when integrated with a heat pump shown.

Although electric vehicles are much more efficient than their internal combustion counterparts there is still some wasted energy. So far in literature heat for a heat pump has been harvested from the motor $[28,29,35]$, the power electronics (including battery) [28,35] and ambient air $[6,28,29,33]$. However, electric vehicles do have other sources of waste heat. de Gennaro et al. showed an average battery to wheel efficiency of $77.8 \%$ at $-7{ }^{\circ} \mathrm{C}$ across the NEDC, WLTC and WMTC drive cycles [27]. This is broken down into losses from the battery, motor and inverter, and the transmission. Williamson performed discharge tests on Lithium Ion batteries and found them to be $97.61 \%$ efficient [36], although the author did not specify the temperature at which these efficiencies were found. He also tested the motor and inverter and found them to have a combined efficiency of approximately $93 \%$ [36] for motoring. The battery, inverter and motor therefore give a combined efficiency of $90.87 \%$, which does not consider losses through the transmission. In a general study on electric vehicles Helms et al. assume a $95 \%$ and $90 \%$ efficiency for the battery and the motor and inverter respectively [26]. In studies on electric vehicles it is common to assume a transmission efficiency of $95 \%[26,37]$.

Another energy saving technique that can be used is cabin air recirculation. As much as $85 \%$ of normally exhausted cabin air can be recycled without building up harmful levels of $\mathrm{CO}_{2}$ [38]. However, this does not consider water vapour which can cause windows to fog at low temperatures. An alternative to recycling could be extracting heat by chilling the cabin exhaust heat, then using that energy in the heat pump. This has been shown by BMW, who have demonstrated a $35 \%$ recovery in the heat from air exhausted from the cabin [39].

Hence the following list of components can be considered as potential heat sources for heat pumps on electric vehicles; 
1. Ambient

2. Battery

3. Inverter

4. Motor

5. Transmission

6. Thermal Battery

7. Cabin exhaust air

In summary, although the studies by Leighton and Ahn took motor (or motor and inverter) into account, these only contribute approximately half of the energy loss in electric vehicles drivetrain. As Ahn showed, increasing the waste heat supplied to a heat pump increases its coefficient of performance. There is an opportunity to explore how additional waste heat sources could contribute to the cold temperature range improvement of electric vehicles. Furthermore, it is expected that increasing the complexity of the heat pump will require additional management of the thermal energy sources to optimise the system's efficiency.

\section{Aims}

Building a system that can extract heat from all of the above sources and manage the heat could be both technically and financially challenging. The work described in this manuscript describes a methodology to find which potential heat sources in a vehicle can give the most benefit to the operation of a heat pump. All possible operational modes will be identified and tested over 3 different drive cycles and 4 ambient temperatures, where it is assumed that all components (except the thermal battery) are in thermal equilibrium with ambient. This is done with the objective of finding which thermal sources allow the heat pump to operate using the minimum electrical energy consumption in low temperature climates. All combinations of thermal sources have been identified and tested since the combination of thermal sources may affect performance and comparing each components performance with the heat pump on an individualistic basis would be neglectful and insufficient. When considering which operational modes and which thermal sources are useful in minimising electrical energy consumption, the cabin temperature and target temperature will be checked to prevent the sacrifice of passenger comfort. This complete process will guide the infrastructure design of a complex heat pump and identify the direction research should take to optimise the mode strategy with which a complex heat pump should be operated. It will also highlight which components should definitely be considered for use when planning a vehicle level heat pump.

The remainder of the paper is split into Model development, Results, Discussion and Conclusion. Section 3 goes into detail on the model used, and explains the methods by which the proposed heat pump will be tested. Section 4 gives an overview of the results and details how the importance of individual thermal sources is quantified. The progress made is discussed in Section 5 along with identification of further work towards developing an optimised controller for the heat pump. The findings and contributions are summarised in Section 6.

\section{Model Development}

A system level vehicle model, similar to that used in [23], generated in the modelling package Dymola, seen in Figure 1, has been used to simulate the prospective benefits of using a heat pump. Dymola is a physical modelling tool based in the Modelica modelling language, with a variety of libraries which assist in modelling large complex systems. The vehicle is simulated at a system level so that the heat pump has the option of extracting heat from multiple sources. The system is able to collect heat from the motor, inverter, thermal battery, gearbox, drive-line (front/rear differentials), cabin exhausted air and ambient. Furthermore the heat pump should be able to provide heat to the cabin. The heat pump should be able to both heat and cool the battery in order to keep its temperature in a range best suited for its optimal performance. Since the functionality of the heat pump is so broad, 
significant effort has been spent on development of the model for a complex heat pump of this nature. The remainder of this section details the heat pump model and sub-models relevant to its operation.

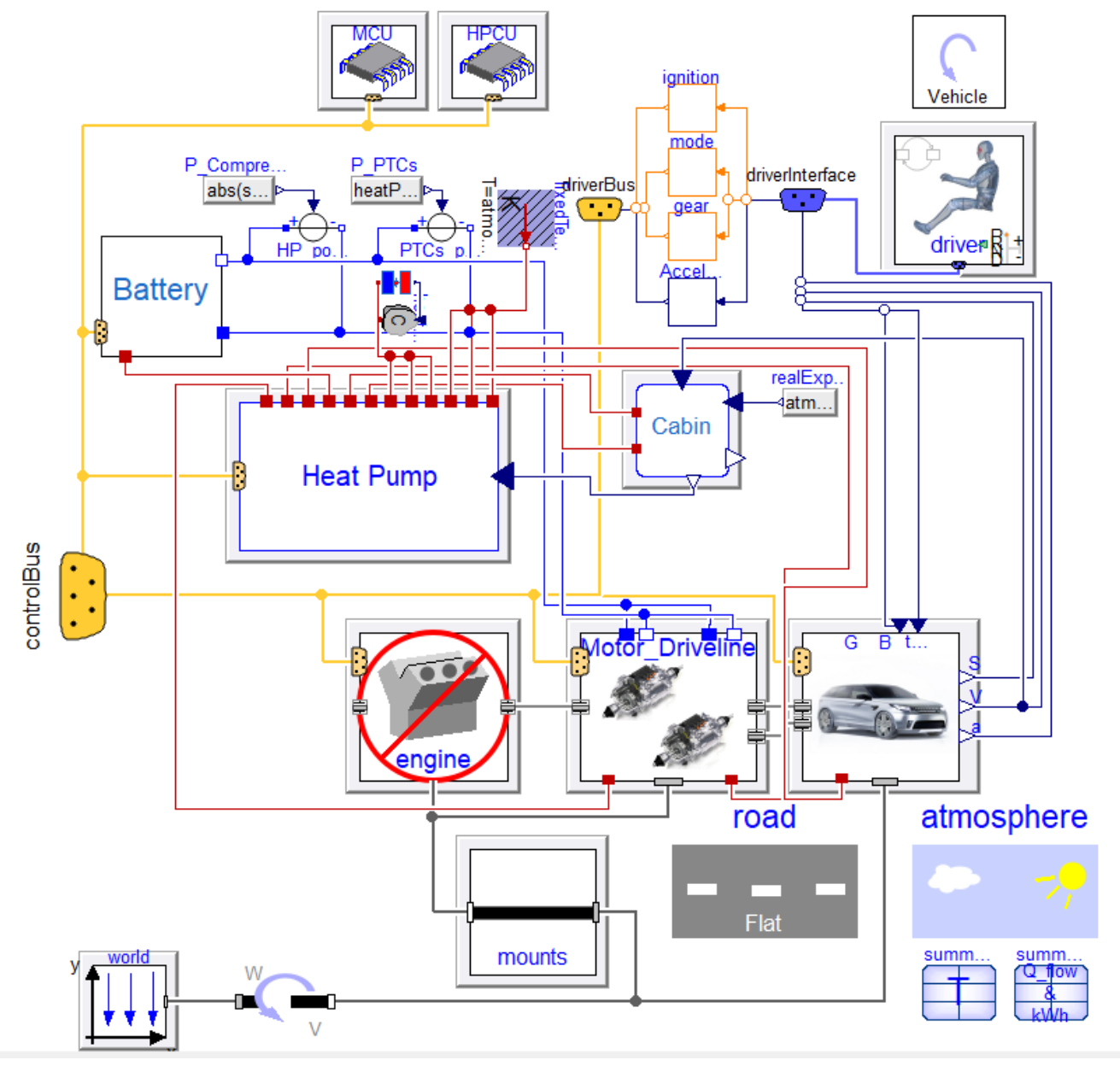

Figure 1. Top level schematic diagram of Dymola vehicle simulation for an EV.

\subsection{Model Details}

The vehicle considered is a passenger vehicle weighing approximately $2500 \mathrm{~kg}$, with a $90 \mathrm{kWh}$ battery pack. It has 4 wheel drive with front and rear motors each capable of $350 \mathrm{Nm}$ of torque and with a single speed gearbox per motor.

The configuration of the heat pump and thermal sources can be seen in Figure 2. In Figure 2 it can be seen that the electric battery, thermal battery and ambient have associated rules regarding there connection to the chiller. In the case of the electric battery these rules are intended to keep the battery within a temperature range best suited to its operation. For the thermal battery the rules ensure that the thermal battery can be fully discharged and then disconnected from the system. With respect to ambient, the rules ensure that the freezing doesn't occur, which would hinder the heat pumps performance. Sections 3.1.1-3.1.7 go on to describe each sub model in further detail. All thermal models, with the exception of the motor, use a single lumped thermal capacitance to predict their temperature. Therefore the temperature of each component is described by,

$$
\frac{d T_{\text {comp }}}{d t}=\frac{Q_{\text {comp }}}{m_{\text {comp }} C_{\text {comp }}}
$$


where $m_{\text {comp }}, C_{\text {comp }}, T_{\text {comp }}$, and $Q_{\text {comp }}$ are the mass, specific heat capacity, temperature and heat flow of each component. During all simulations it is assumed that all components are in thermal equilibrium with ambient. Further model details for each component are described in the following subsections.

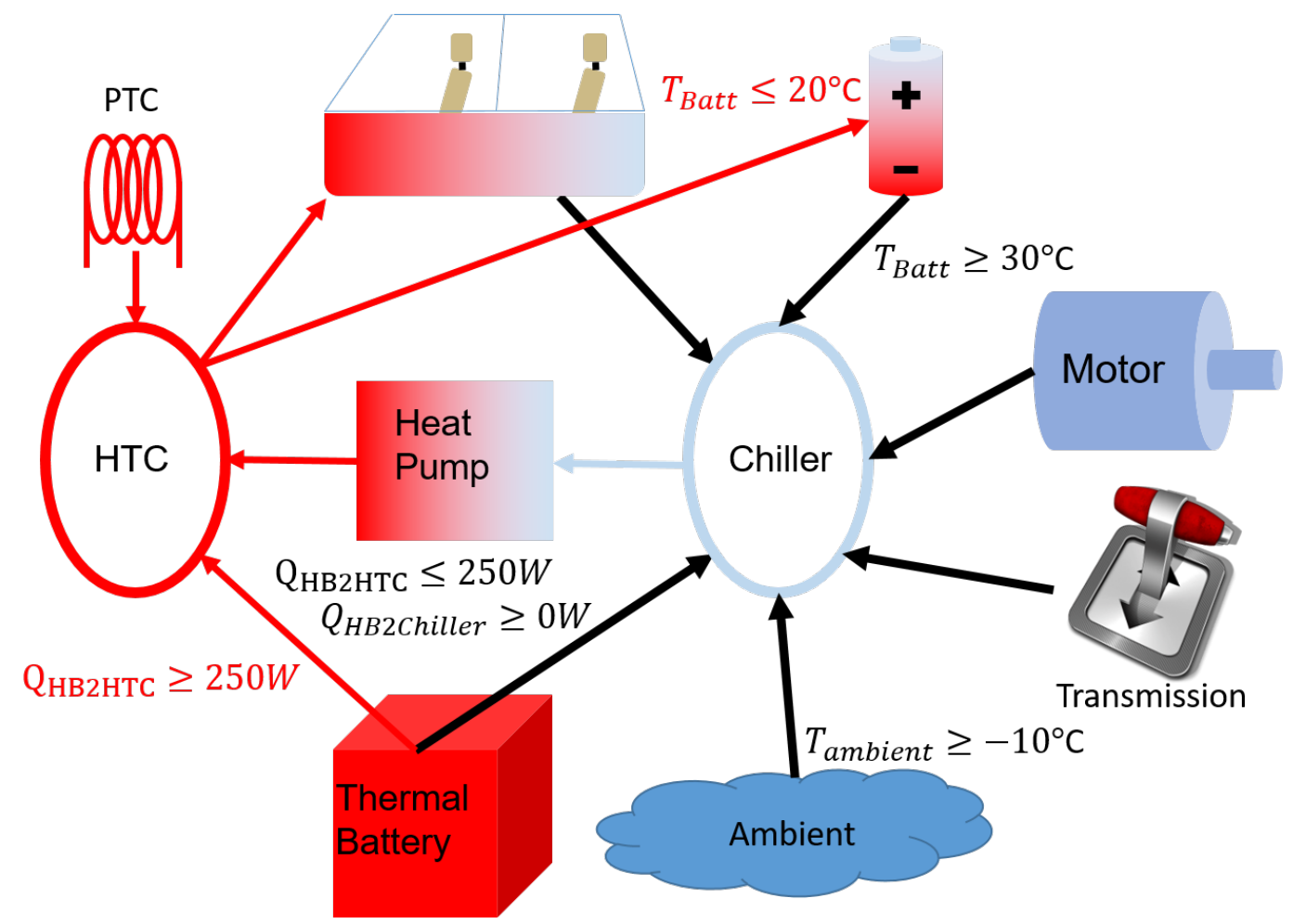

Figure 2. Schematic of thermal contributors to the heat pump, where HTC is the high temperature coolant circuit used for battery and cabin heating.

\subsubsection{Battery}

In the battery, Ohmic heating from a 1st order RC network model is used to predict heat generation.

The heat is stored in a thermal mass, which represents the entire pack. Heat can be given to, or taken from, the heat pump, while also being lost to ambient. The heat flow for the battery is described as

$$
Q_{\text {batt }}=I^{2} R(T, S O C)+Q_{T M}^{\text {batt }}+Q_{a m b i e n t}^{\text {batt }}
$$

where $I$ and $R(T, S O C)$ are the battery current and the battery resistance, which is a function of both temperature and state of charge (SOC), respectively. Here $R(T, S O C)$ is given by the sum of $R_{0}(T, S O C)$ and $R_{p}(T, S O C)$, where the dependancies on temperature and SOC are controlled by a lookup table. $Q_{T M}^{\text {batt }}$ is the heat flow through thermal management, in the case of the battery this is either receiving heat from, or supplying heat to, the heat pump. Finally $Q_{a m b i e n t}$ is described by Equation (4),

$$
Q_{\text {ambient }}=G_{\text {effective }}(v) \times\left(T_{\text {battery }}-T_{\text {ambient }}\right)
$$

where $G_{\text {effective }}(v)$ is the effective thermal conductance between the battery and ambient, which (in the case of the battery) is a function of vehicle speed.

The battery, like all components, is initially in thermal equilibrium with ambient. It has been shown that preheating the battery can reduce total financial cost of operation by up to $34 \%$ [40], however, no preheating is assumed here to conform to a worst case scenario. The consequence of this is that it cannot act as a heat source for the heat pump while its temperature is low as this hinders its performance. To avoid cooling the battery at low temperatures and suffering from poor performance, the battery is heated when its temperature is below $20^{\circ} \mathrm{C}$ and cooled when its temperature exceeds 
$30{ }^{\circ} \mathrm{C}$. This means that for the majority of cases, the battery is being heated, rather than used as a heat source, however in milder climate conditions it may be used as a heat source.

\subsubsection{Motor}

For the motor, heat is assumed to be generated through a combination of losses and is approximated using a two dimensional efficiency map, where it is assumed that some heat is lost to ambient. Furthermore it is assumed that the dominant cause of inefficiency is ohmic losses in the windings. There is a thermal mass for both the core and the windings, where the heat is generated. The windings are connected to the thermal management system and also dissipate heat to ambient. As such the heat flow is described by,

$$
Q_{\text {motor }}=Q_{\text {windings }}+Q_{\text {core }}+Q_{T M}^{\text {motor }}+Q_{\text {ambient }}
$$

where

$$
Q_{\text {windings }}=(1-\eta) \tau \omega \text {. }
$$

Here $\eta, \tau$ and $\omega$ are the motor's efficiency, temperature, torque and speed respectively. For each simulated time step $\eta$ is found using an efficiency map with inputs; voltage, torque and speed. $Q_{T M}^{\text {motor }}$ is the heat flow due to thermal management of the motor. This is the heat extracted by the chiller loop of the heat pump. $Q_{\text {core }}$ is the heat flow between the windings, where the heat is generated and the motor core. This is given by,

$$
Q_{\text {core }}=G_{\text {core2windings }}\left(T_{\text {core }}-T_{\text {windings }}\right) \text {, }
$$

where $G_{\text {corezwindings }}$ is a fixed conduction coefficient with a value equal to $1.75 \mathrm{WK}^{-1}$. Finally $Q_{a m b i e n t}^{\text {motor }}$ is defined in Equation (8).

$$
Q_{\text {ambient }}^{\text {motor }}=G_{\text {motor2ambient }}\left(T_{\text {ambient }}-T_{\text {motor }}\right),
$$

where $G_{m o t o r 2 a m b i e n t}$ is a fixed conduction parameter with a value equal to $10 \mathrm{WK}^{-1}$.

\subsubsection{Thermal Storage}

The heat flow from the thermal battery is described by,

$$
Q_{T B}=Q_{T M}^{T B} .
$$

where $Q_{T B}$ is the heat flow out of the heat battery, and $Q_{T M}^{T B}$ is the heat flow from the thermal battery to the thermal management system (it is assumed that the thermal battery is well insulated and therefore thermally isolated from ambient). It gives all of its heat to the thermal management system. The specific heat capacity, however, needs to be treated differently to other components, as it will experience a phase change where a large amount of energy is released. A lookup table is used to control the heat capacity as a function of temperature, this allows for the latent heat to be accounted for. This is done by increasing the specific heat value to that of the latent heat value over a $1{ }^{\circ} \mathrm{C}$ window at the materials melting point, a similar approach was taken by Taylor et al. in [41].

\subsubsection{Transmission}

The models for the gearbox and differential are similar to the model for the motors. The heat flow for each is given below:

$$
\begin{gathered}
Q_{\text {gearbox }}=\left(1-\eta_{\text {gearbox }}\right) \tau_{\text {gearbox }} \omega_{\text {gearbox }}+Q_{\text {ambient }} \\
Q_{\text {diff }}=\left(1-\eta_{\text {diff }}\right) \tau_{\text {diff }} \omega_{\text {diff }}+Q_{\text {ambient }} .
\end{gathered}
$$


Here all of the variables have their usual meanings and $\eta$ for both the gearbox and differentials are dependent on torque, temperature and speed. This dependencies are accounted for using lookup tables from representative vehicle data.

\subsubsection{Cabin}

The cabin has a target temperature of $22{ }^{\circ} \mathrm{C}$ which can be used to assess the thermal comfort achieved when using the heat pump. The cabin model can be seen in Figure 3. An infinite air source with ambient temperature is taken into the cabin and heated in the eAC component, seen in Figure 3. The heated air is then pumped into the cabin, where one air volume and heat capacitance are used to measure the cabin temperature. This air volume has four modes of losing heat: convection to ambient through panels, thermal exchange with soft furnishings, thermal exchange with hard furnishings, and cabin air exhaust. The convection to ambient through the exterior surfaces is modelled using a variable thermal conductance with dependency on vehicle speed. The model uses two heat capacitances for air to hard furnishings (such as dashboard panels, glass etc.) and soft furnishings (such as the seats, carpet etc.), with thermal resistances between the air and these components. Finally there are two volumes representing the air in the cabin, one large and one small. The larger air volume represents the majority of the cabin where the target temperature is imposed. The smaller air volume is used to harvest cabin exhaust waste heat, here up to $30 \%$ of the heat can be extracted and used in the heat pump.

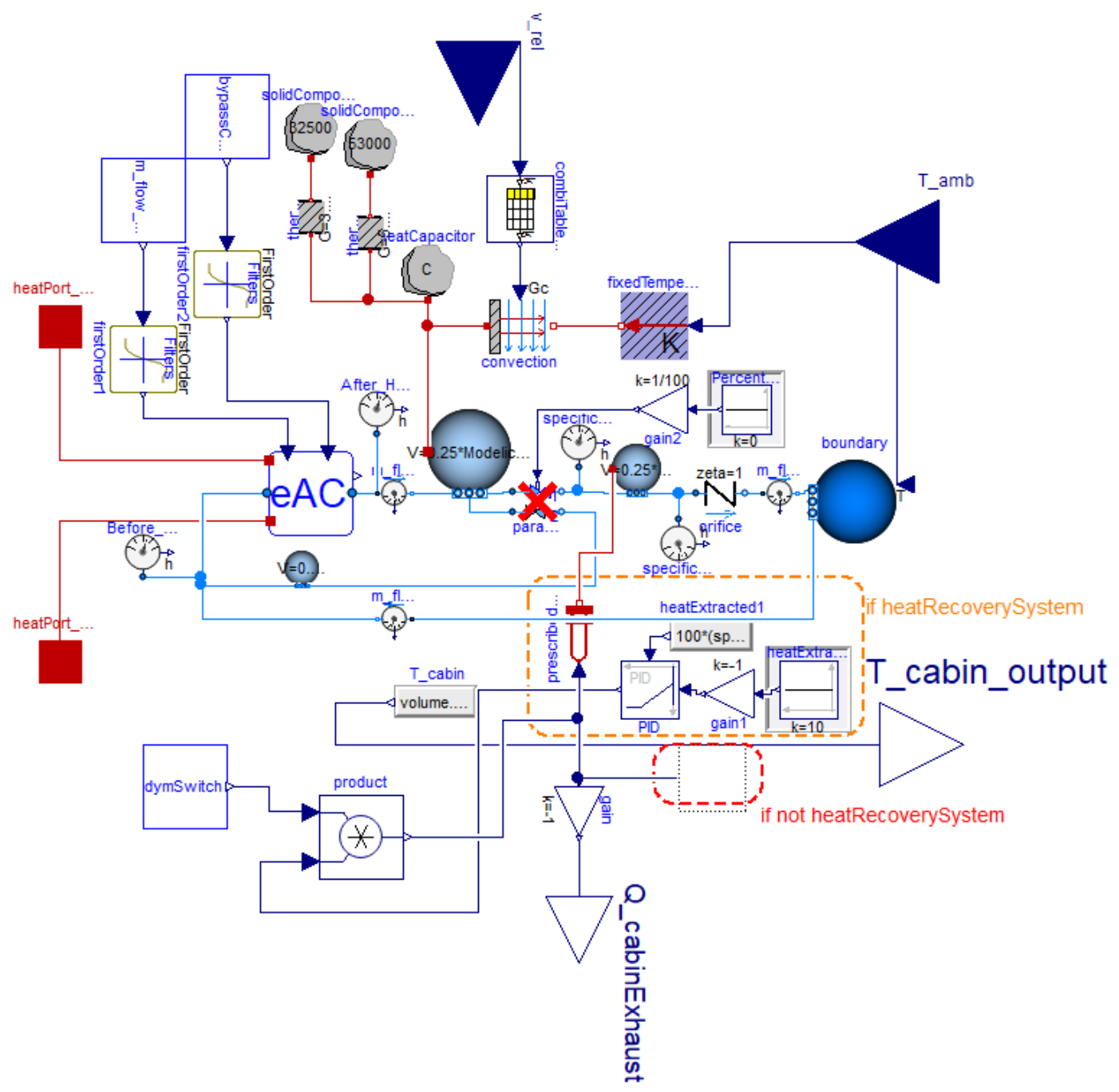

Figure 3. Cabin model. 


\subsubsection{Heat Pump}

The heat pump has the ability to dynamically connect and disconnect to multiple components around the vehicle with the aim of maximising the vehicle's thermal management efficiency. The battery, heat battery and ambient require additional logic checks to decide whether the component should be connected to the high temperature circuit or the chiller circuit. Since the battery can either be cooled or heated, there exists some logic to control when this should happen. When the battery is below $20^{\circ} \mathrm{C}$ it is connected to the HTC and receiving heat, when its temperature rises above $30{ }^{\circ} \mathrm{C}$ the battery is connected to the chiller and cooled. In between these temperatures the battery is isolated from the heat pump. Similarly the heat battery is initially connected to the HTC where it delivers heat, but when its heat delivery drops below $250 \mathrm{~W}$ the heat battery is swapped to the chiller, where it delivers the remainder of its energy. Finally, ambient is only used as a heat source when the ambient temperature is above $-10{ }^{\circ} \mathrm{C}$. These logical conditions are shown in Figure 2.

The heat pump model is further broken down into three levels, seen in Figure 4, with the following purposes; interfacing the vehicle components with the heat pump coolant loops, interfacing the coolant loops with the refrigeration cycle and simulating the refrigeration cycle itself.

The top level model of the heat pump, seen in Figure 4a, contains the interfaces between the components and the heat pump. The thermal switches can be seen across the top of Figure $4 a$, these are part of the control system which allows components to be connected and disconnected from the heat pump. Each switch is a variable thermal conductor which can be varied in value to control the amount of heat extraction from each component or isolate the component from the heat pump.

The middle level model, seen in Figure $4 \mathrm{~b}$ of the heat pump contains the models for the high temperature circuit (HTC), chiller and PTC heater. The HTC has an operational target temperature of $90{ }^{\circ} \mathrm{C}$ and is used to extract heat from the condenser side of the refrigeration circuit and distribute it to the cabin and battery. Finally the HTC receives heat from the PTC heater and the thermal battery. On the other side of the refrigeration circuit, the evaporator is connected to the chiller loop. The chiller loop has an operational temperature of $-10{ }^{\circ} \mathrm{C}$ and is able to extract heat from the motor, gearbox, differentials, battery, cabin exhaust air, thermal battery and ambient.

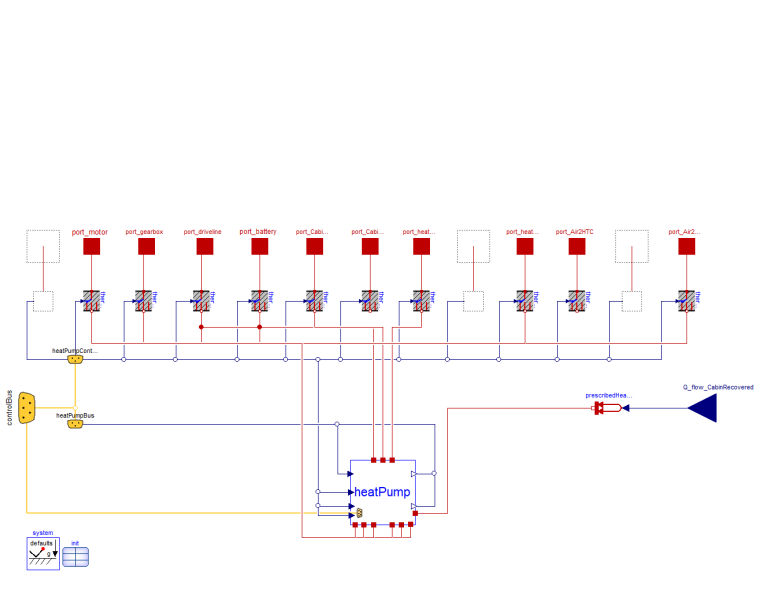

(a)

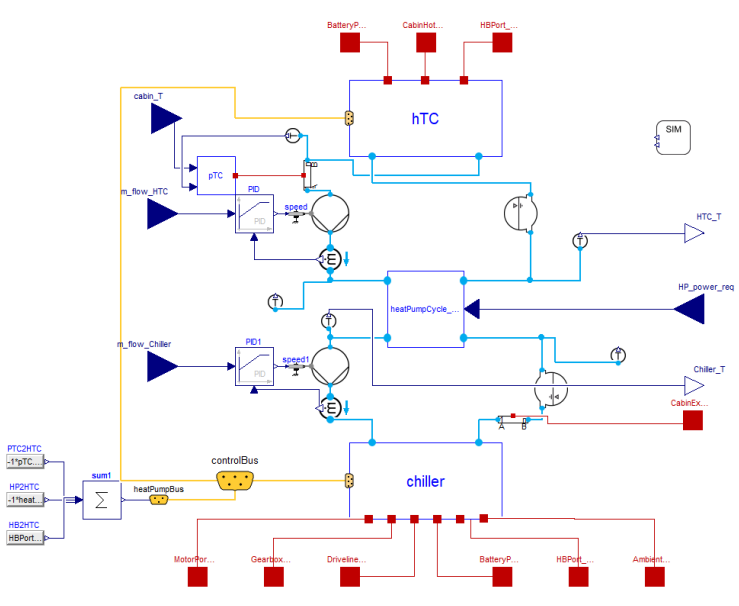

(b)

Figure 4. Cont. 


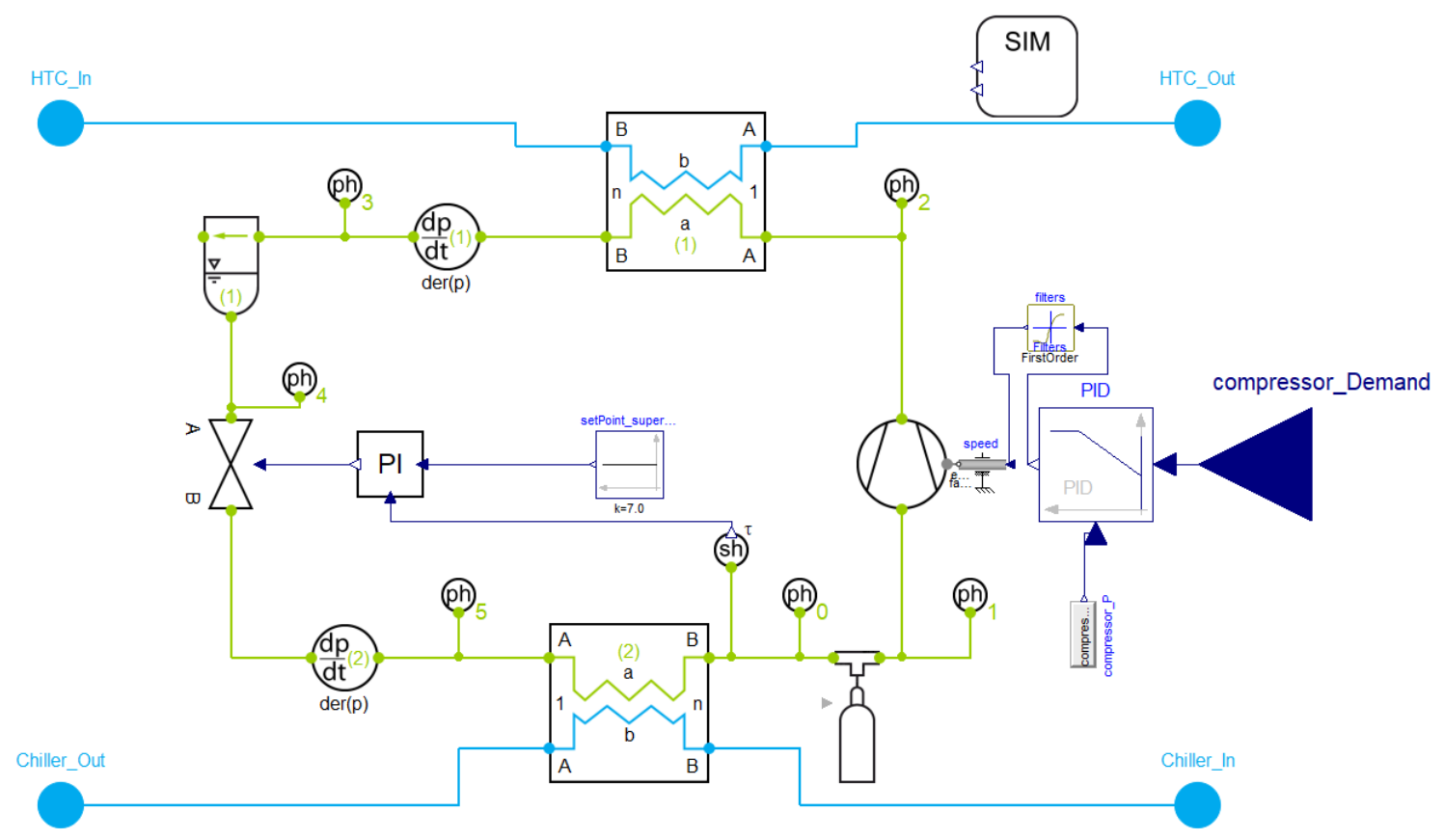

(c)

Figure 4. The top level of the heat pump model, (a) is used to connect vehicle components to the heat pump via switches seen across the top of the figure. These switches are controlled by external controller to either connect or isolate a component to/from the heat pump. The middle level of the heat pump model, (b) is used to interface the components with the coolant circuits contained in the HTC and Chiller components labelled in the figure. Here parametrised heat exchangers control the thermal exchange between the component and the coolant loops. The lowest level of the heat pump model, (c) contains the refrigeration circuit, moves heat from the chiller loop to the HTC loop via the evaporator and condenser. The refrigeration loop was modelled using the Thermal Systems library from TLK Thermo.

The lowest level of the model, seen in Figure 4c, is the refrigeration circuit. The refrigeration circuit contains the evaporator, condenser, expansion valve compressor, and some control components. The compressor is controlled by a proportional-integral-derivative (PID) controller which takes a demand from an overall supervisory controller, and uses the current power consumption of the compressor to control the compressor speed. The supervisory controller has the ability to request that the compressor uses up to $2.5 \mathrm{~kW}$ of power. In the top corner of Figure $4 \mathrm{c}$ the System Information Manager (SIM) can be seen, this is where the heat pump's refrigeration and coolant fluids are set. For this work R134a was used as the refrigerant and water/glycol mix as the coolant.

\subsubsection{PTC Heater}

The PTC heater has a maximum heating capability of $4 \mathrm{~kW}$, and is assumed to be $100 \%$ efficient at generating heat. Combined with the maximum power consumption of $2.5 \mathrm{~kW}$ of the compressor, the heating, ventilation and air-conditioning (HVAC) system has a maximum demand of $6.5 \mathrm{~kW}$. It is controlled using a PID controller with the aim of heating the cabin to target temperature via the HTC, it is also controlled to shut off when the HTC reaches its operational temperature.

\subsection{Parametrisation}

The drivetrain for the vehicle is based on an existing vehicle and so can be validated using WLTP at $23{ }^{\circ} \mathrm{C}$, i.e., with no HVAC requirements. The thermal side however represent a new proposed 
system, not currently realised on any vehicle or in any physical form. Correspondingly, the parameters surrounding the thermal systems are estimated and approximated. In some cases (due to the size of the model each case will not be specified), such as the thermal conductances give in Equations (7) and (8), this is done by taking sensible approximations about the size, construction and material found in the motors. In other cases, such as the heat exchangers found in the HTC and Chiller components of Figure $4 \mathrm{~b}$, parameters were based on existing components found in comparable vehicles.

Regarding the battery, the lookup tables used for cell $O C V, R_{0}, R_{p}$ and $C_{p}$ were parametrised using data from cell cycling experiments performed on Dow Kokam 40 cells. This data was provided and analysed by Yashraj Tripathy.

\subsection{Model Usage Cases}

The system has been tested on three drive cycles, WarmUp, New European Drive Cycle (NEDC), and World Harmonised Light Vehicle Test Procedure (WLTP), each one more dynamic than the previous. This is important for evaluating the systems response to varying real world use cases. Firstly the system was tested using the simple cruising profile (WarmUp), this consisted of a $50 \mathrm{kmh}^{-1}$ cruise for $30 \mathrm{~min}$, followed by a $100 \mathrm{kmh}^{-1}$ cruise for $30 \mathrm{~min}$, then $30 \mathrm{~min}$ at rest, $75 \mathrm{~km}$ in total. This cycle is designed to test the systems warm up capability and steady state power consumption. Simulations were also carried out on the NEDC $(11 \mathrm{~km})$ and WLTP $(23.3 \mathrm{~km})$ drive cycles. The NEDC is semi-dynamic, it has several acceleration and braking sections, but also maintains constant speeds for considerable time. The WLTP cycle on the other hand is more dynamic, with no steady state sections (i.e., at no point is a speed maintained for more than $5 \mathrm{~s}$ unless stationary).

With multiple heat sources available for the heat pump to harvest from, a selection of operational modes becomes available, each one corresponding to a different combination of heat sources being connected to the heat pump. Since the efficiency of components, such as the gearbox and battery, is dependent on temperature and power, it is expected that as the dynamics of the drive cycle increases (with more acceleration instances requiring more power), different operational modes will be required to minimise the total electrical energy consumption.

It is also expected that operational modes that harvest less energy will be more efficient at higher ambient temperatures, where less heating is needed. This is expected since the cabin will warm up faster and spend more time at steady state, with less heat required to maintain the temperature difference between ambient and the cabin. Correspondingly, when the ambient temperature is lower, it is expected that operational modes that harvest more energy will be favoured. To investigate this, each drive cycle is tested at $-20^{\circ} \mathrm{C},-10{ }^{\circ} \mathrm{C}, 0{ }^{\circ} \mathrm{C}$ and $10{ }^{\circ} \mathrm{C}$.

A set of operational modes needs to be produced based on the list of heat sources independently available, given in Section 1.2. Producing a complete set of operational modes covering all possible permutations would lead to $2^{7}$ or 128 different operational modes, which need testing on 3 cycles each at 4 temperatures, giving 1536 tests. This can be reduced by making some assumptions to remove some variables. This has already been done in the case of the transmission which is the combination of the gearbox and the differential. Since all examples of heat pumps given in the introduction use ambient as a heat source, all operational modes will include ambient extraction by default. However when ambient temperature falls below the target temperature of the chiller, it will not be used as a heat source. The motor and inverter are similar in that their losses are dominated by ohmic heating and so could also be combined as a single heat source. In the context above, a single heat source means that they share the same coolant circuit and the individual items in that heat source contribute together to the heat extracted by the heat pump. These assumptions allow the list of heat sources to be reduced from 7 to 5 , the reduced list is;

1. Motor

2. Transmission

3. Battery

4. Thermal Battery 


\section{Cabin Exhaust}

By defining 2 modes of operation for each component, on and off (labelled 1 and 0), which refers to their connection to the heat pump, where off is thermally isolated from the heat pump and on is thermally managed by the heat pump, a set of operational modes can be constructed. Since each component has a binary control and there are 5 individual components, there are $2^{5}$ unique operational modes which can be seen in Table 1 . The operational modes of the heat pump are also compared to two baseline cases, no heating and PTC heating only, which has been the standard in electric vehicles so far. The operational modes are created by listing the numbers 0 to 31 as binary numbers $(00000,00001, \ldots$, 11111) where each digit represents the state of the components given in the list above. This allows for all possible combinations of thermal contributors to be tested.

Table 1. List of heat sources, their operational mode options, and an example of how each operational mode is constructed.

\begin{tabular}{|c|c|c|c|c|c|c|c|c|c|c|c|c|c|c|c|c|c|c|c|c|c|c|c|c|c|c|c|c|c|c|c|c|}
\hline \multirow{2}{*}{ Heat Source } & \multicolumn{32}{|c|}{ Operational Mode } \\
\hline & 0 & 1 & 2 & 3 & 4 & 5 & 6 & 7 & 8 & 9 & 10 & 11 & 12 & 13 & 14 & 15 & 16 & 17 & 18 & 19 & 20 & 21 & 22 & 23 & 24 & 25 & 26 & 27 & 28 & 29 & 30 & 31 \\
\hline Motor and Inverter & 0 & 0 & 0 & 0 & 0 & 0 & 0 & 0 & 0 & 0 & 0 & 0 & 0 & 0 & 0 & 0 & 1 & 1 & 1 & 1 & 1 & 1 & 1 & 1 & 1 & 1 & 1 & 1 & 1 & 1 & 1 & 1 \\
\hline Thermal Battery & 0 & 0 & 0 & 0 & 0 & 0 & 0 & 0 & 1 & 1 & 1 & 1 & 1 & 1 & 1 & 1 & 0 & 0 & 0 & 0 & 0 & 0 & 0 & 0 & 1 & 1 & 1 & 1 & 1 & 1 & 1 & 1 \\
\hline Electric Battery & 0 & 0 & 0 & 0 & 1 & 1 & 1 & 1 & 0 & 0 & 0 & 0 & 1 & 1 & 1 & 1 & 0 & 0 & 0 & 0 & 1 & 1 & 1 & 1 & 0 & 0 & 0 & 0 & 1 & 1 & 1 & 1 \\
\hline Transmission & 0 & 0 & 1 & 1 & 0 & 0 & 1 & 1 & 0 & 0 & 1 & 1 & 0 & 0 & 1 & 1 & 0 & 0 & 1 & 1 & 0 & 0 & 1 & 1 & 0 & 0 & 1 & 1 & 0 & 0 & 1 & 1 \\
\hline Cabin Exhaust & 0 & 1 & 0 & 1 & 0 & 1 & 0 & 1 & 0 & 1 & 0 & 1 & 0 & 1 & 0 & 1 & 0 & 1 & 0 & 1 & 0 & 1 & 0 & 1 & 0 & 1 & 0 & 1 & 0 & 1 & 0 & 1 \\
\hline
\end{tabular}

The possible operational modes were tested and initially compared to two baseline cases discussed further in Section 4. Secondly, additional analysis was conducted to find trends in when individual operational modes perform well and when they do not. To ensure that the cabin temperature is not compromised by seeking modes which use the least power, the operational modes compared are limited to ones that meet cabin target temperature, or choosing the one which reaches the highest cabin temperature if the target cannot be met.

Since the drive cycles tested have different characteristic times according to their dynamics, the frequency of evaluating which operational mode is performing best should be explored. To investigate the effect of switching frequency on mode evaluation and comparison 6 different interval lengths have been chosen over which the energy usage of each operational mode will be considered and compared. The lengths of these intervals are 5, 30, 60, 120, 300 and $600 \mathrm{~s}$. The method used to choose which operational mode performs best during these periods is explained in Section 4.2.

\section{Results}

\subsection{Baseline}

The simulation has been run in two baseline operational modes, PTC heating on and PTC heating off, tested at $10{ }^{\circ} \mathrm{C}, 0{ }^{\circ} \mathrm{C},-10^{\circ} \mathrm{C}$ and $-20^{\circ} \mathrm{C}$ on the WarmUp, NEDC and WLTP cycles. This establishes how much energy the vehicle uses as a function of temperature and how much HVAC energy is needed when the heat pump is not in use. The heat pump system consumes a maximum of $6.5 \mathrm{~kW}$, as described in Section 3.1.7, however as the heat pump is switched off during the benchmarking, the PTC maximum power is increased from $4 \mathrm{~kW}$ to $6.5 \mathrm{~kW}$ to account for the deficit in maximum HVAC power consumption. The results of these baseline tests can be seen in Figure 5 . The boundaries thus created by the lines depicting heating on and heating off for each of the drive cycles give the potential operating area to be explored. It is expected that the use of the heat pump will cause the total electrical energy consumption, i.e., the HVAC energy consumption plus the drive cycle energy consumption, to fall between these lines, Improvements in control will further improve total electrical energy consumption, approaching the heating off results. 


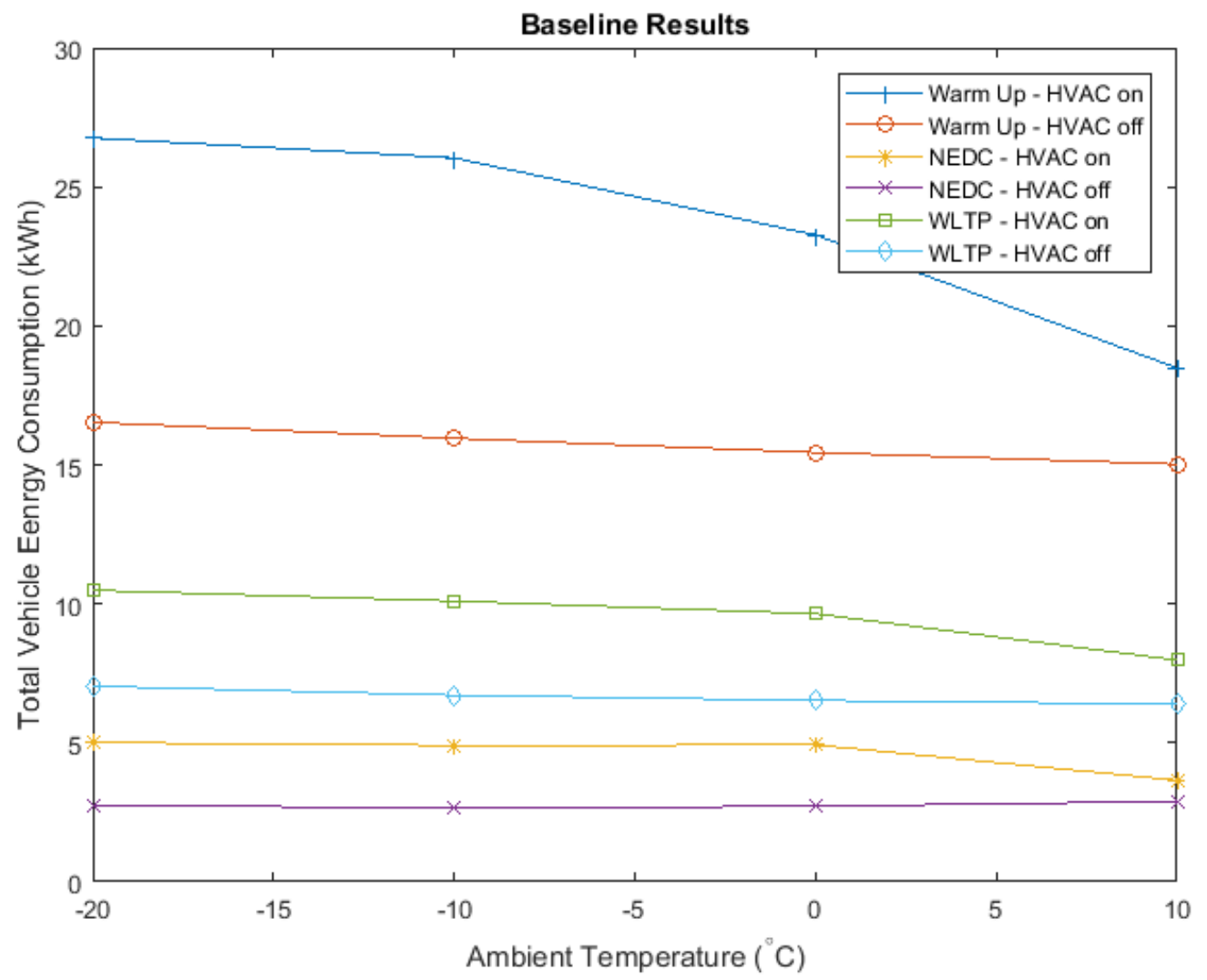

Figure 5. Energy consumption used when the vehicle completed drive cycles at different temperatures with heating on and off.

\subsection{Heat Pump with Variable Heat Sources}

The simulation was then run for all 32 operational modes. From each scenario the operational mode which used the least energy while reaching cabin target temperature (or the mode which reached the highest cabin temperature if the target was not met) was identified and compared to the baseline energy consumptions, as shown in Figure 6. From Figure 6 it can be seen that there is not one operational mode that performs best over all circumstances. The average energy saving over all scenarios was $14.8 \%$, while the maximum and minimum energy savings were $24 \%$ at $0{ }^{\circ} \mathrm{C}$ on the WarmUp drive cycle and $7.7 \%$ at $-10{ }^{\circ} \mathrm{C}$ on the WLTP drive cycle respectively.

Once all simulations were complete the results were analysed to identify how each operational mode performed at different points during the drive cycle. As discussed in Section 3.3 the switching frequency was investigated by splitting the drive cycles into intervals of different lengths, then deciding which operational mode performed best for each interval. To calculate energy consumption during each interval the power was integrated according to the selected interval lengths, giving the total electrical energy consumption values per interval through the drive cycle. Before the energy consumption for each mode per interval is compared, the list of potential operational modes to compare is reduced. This is achieved by limiting the operational modes to only those which meet the cabin target temperature of $22{ }^{\circ} \mathrm{C}$, this step is designed to ensure that cabin comfort is not sacrificed in the pursuit of reduced energy consumption. where the target temperature is not met, mode choice is limited to the single mode which achieves the highest cabin temperature, these cases are identified as red dots in Figures 7-9. In the cases where cabin temperature meets the target and a reduced list is formed, the mode which uses the least energy in a given interval is chosen as the best performing operational mode for that interval. This process can be summarised into the following procedure; 
1. Run all 32 operational modes over all drive cycles and temperatures.

2. For each scenario (temperature, cycle), reduce list of modes to those which reach cabin target temperature.

3. If cabin temperature is not reached, limit operational mode choice to the one with highest cabin temperature.

4. Identify best performing mode during each interval of drive cycle.

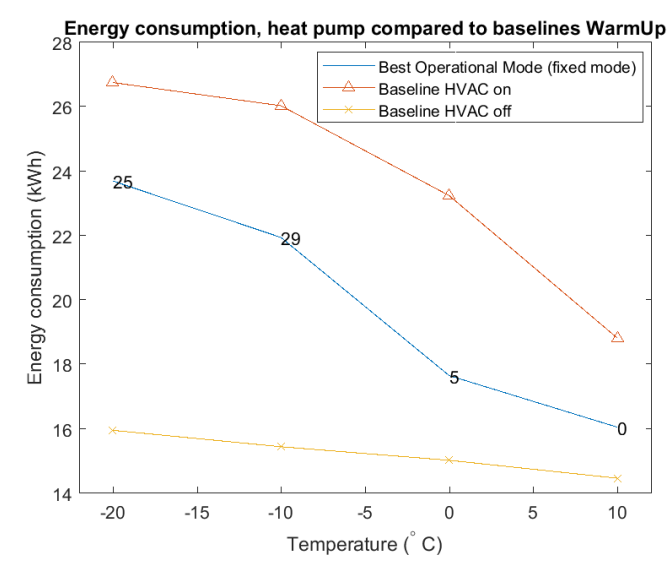

(a)

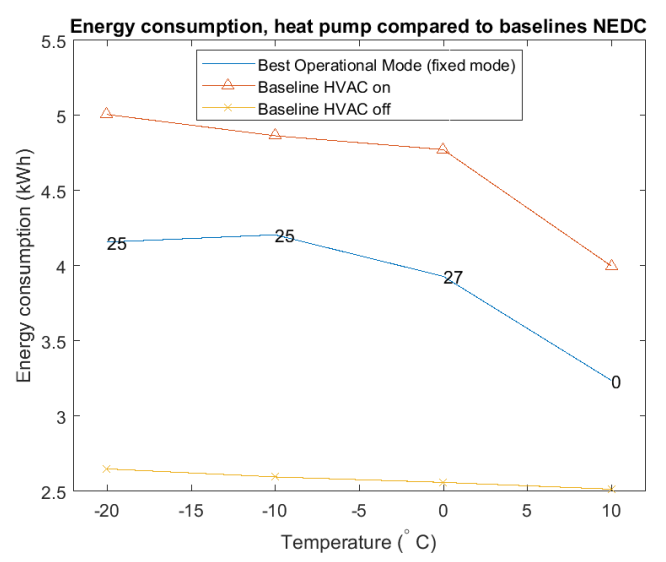

(b)

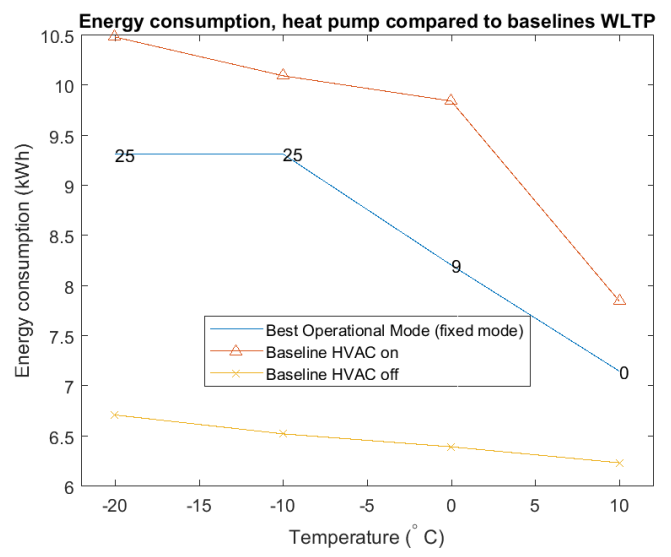

(c)

Figure 6. Comparison of total electrical energy consumption over WarmUp, NEDC and WLTP ((a-c) respectively) of the best single operational mode during each scenario to the baseline results of HVAC on and HVAC off.

This is repeated for six interval lengths; $5 \mathrm{~s}, 30 \mathrm{~s}, 60 \mathrm{~s}, 120 \mathrm{~s}, 300 \mathrm{~s}$ and $600 \mathrm{~s}$. The result of this is a selection of operational modes which perform well given certain vehicle conditions. From this, trends can be extracted which could help to design or dynamically control a complex heat pump. Selections of well performing modes can be seen in Figures 7-9; where the $30 \mathrm{~s}$ interval length was chosen as an example. Here the best operational mode during each $30 \mathrm{~s}$ interval is shown and overlaid with the corresponding drive cycle.

From Figures 7-9 it can be seen that there is not one operational mode that gives a minimum total electrical energy consumption over the entire drive cycle. Further analysis has been performed to explore the conditions which make operational modes or the use of individual components advantageous. Here the $30 \mathrm{~s}$ interval length has been presented. as the increased frequency of a shorter interval length offers more operational mode data points to qualitatively assess trends, while $5 \mathrm{~s}$ interval lengths become crowded making it more difficult to identify trends. 


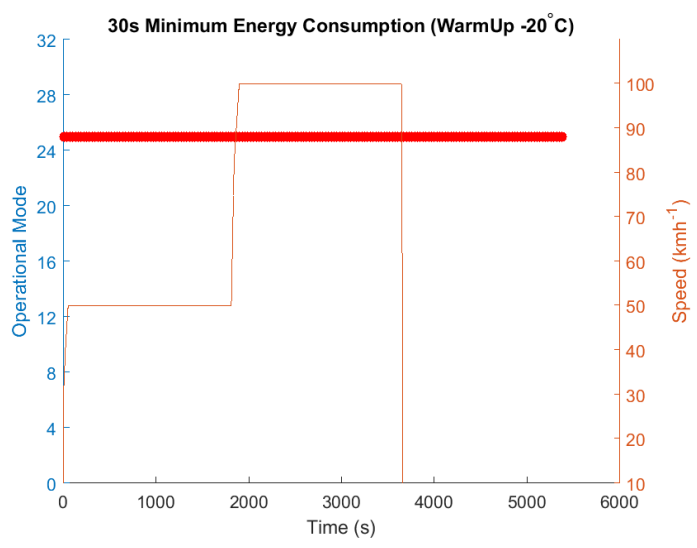

(a)

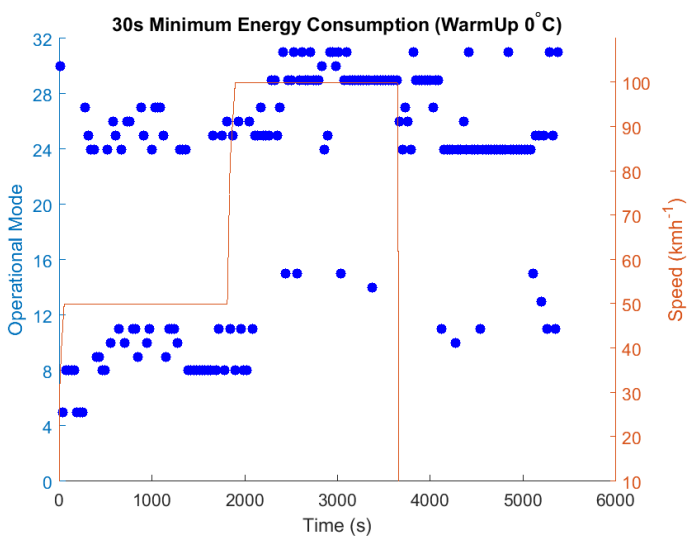

(c)

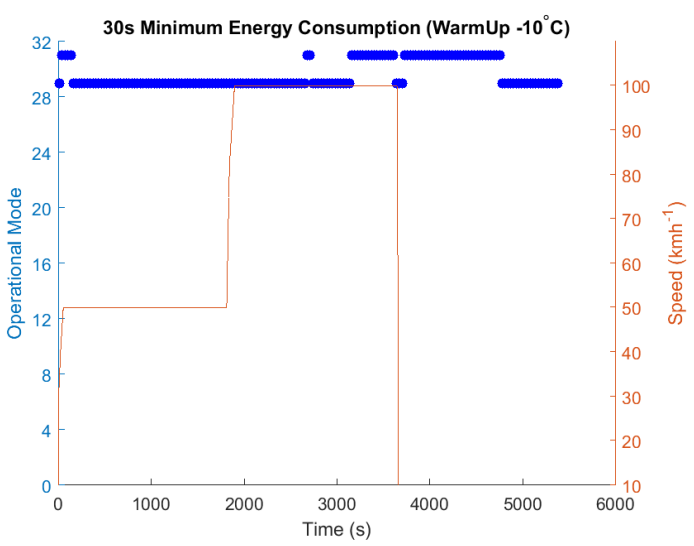

(b)

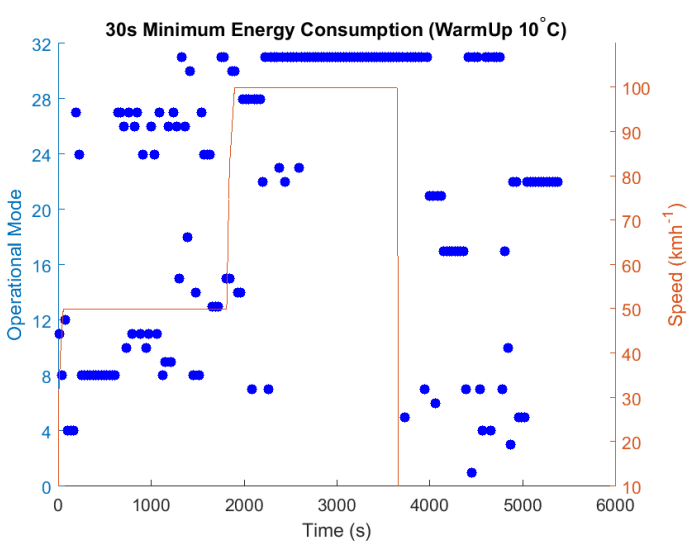

(d)

Figure 7. The best operational mode during $30 \mathrm{~s}$ intervals as a function of time is shown through the Warm up drive cycle over temperatures $-20^{\circ} \mathrm{C}(\mathbf{a}),-10^{\circ} \mathrm{C}(\mathbf{b}), 0^{\circ} \mathrm{C}(\mathbf{c})$ and $10^{\circ} \mathrm{C}(\mathbf{d})$. Blue dots show the operational mode which used the least energy during that $30 \mathrm{~s}$ interval. This has been overlaid with the Warm up drive cycle. Red dots indicate when no operational mode met cabin target temperature, blue dots indicate multiple operational modes met cabin target temperature.

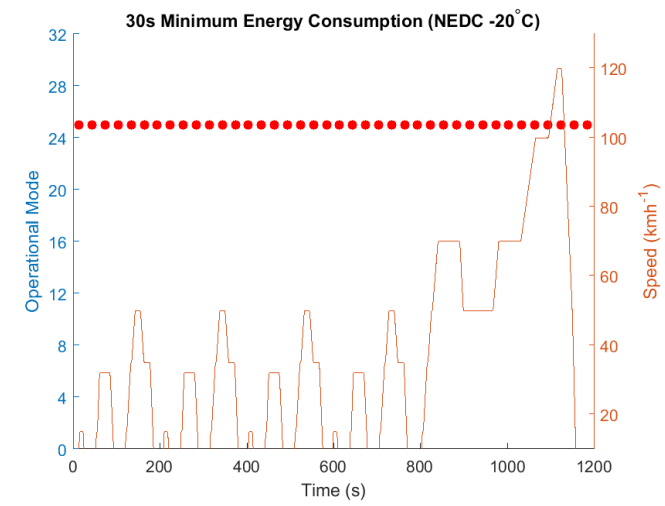

(a)

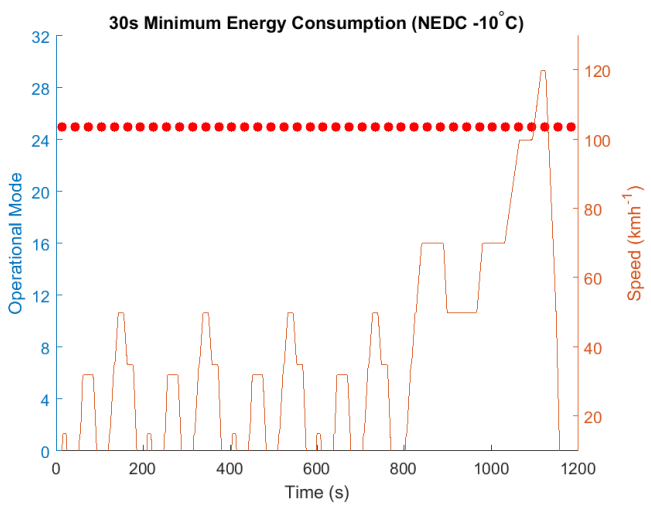

(b)

Figure 8. Cont. 


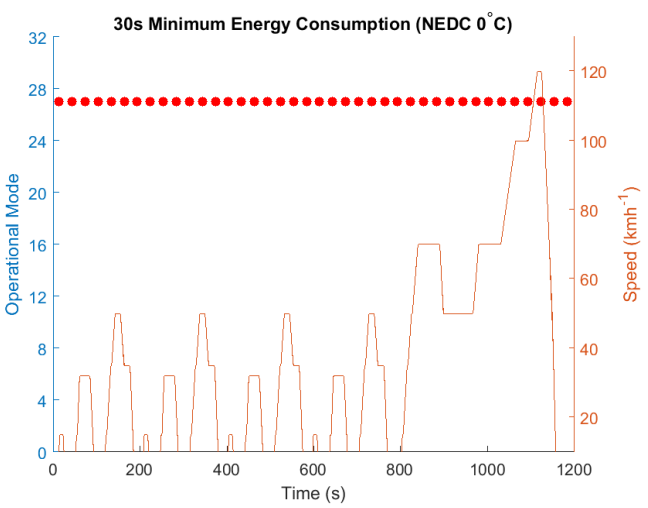

(c)

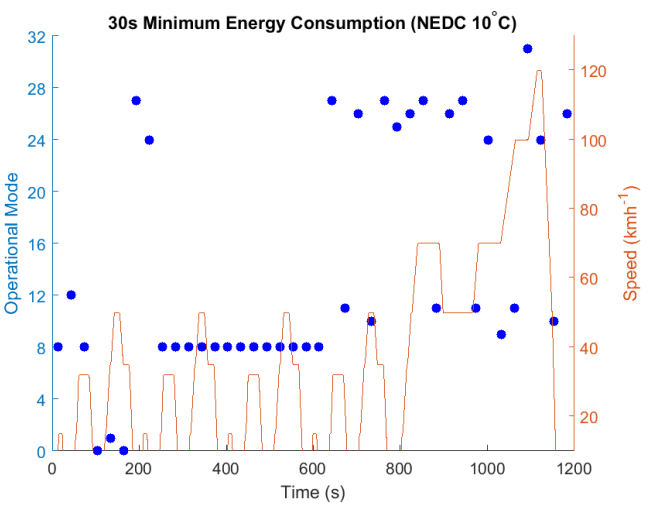

(d)

Figure 8. The best operational mode during $30 \mathrm{~s}$ intervals as a function of time is shown through the Warm up drive cycle over temperatures $-20^{\circ} \mathrm{C}(\mathbf{a}),-10{ }^{\circ} \mathrm{C}(\mathbf{b}), 0^{\circ} \mathrm{C}(\mathbf{c})$ and $10{ }^{\circ} \mathrm{C}(\mathbf{d})$. Blue dots show the operational mode which used the least energy during that $30 \mathrm{~s}$ interval. This has been overlaid with the NEDC drive cycle. Red dots indicate when no operational mode met cabin target temperature, blue dots indicate multiple operational modes met cabin target temperature.

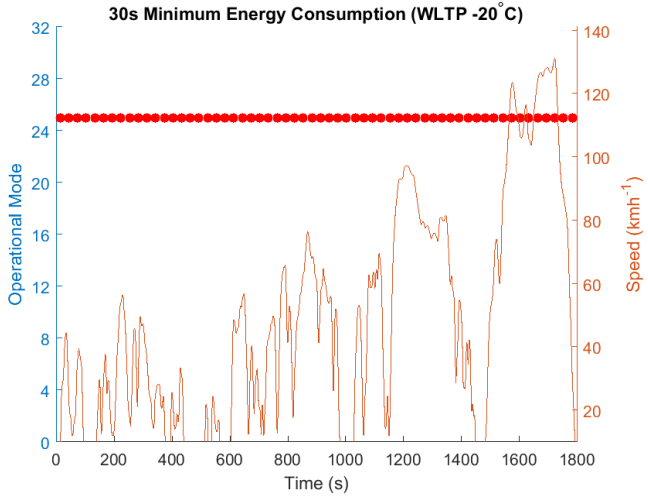

(a)

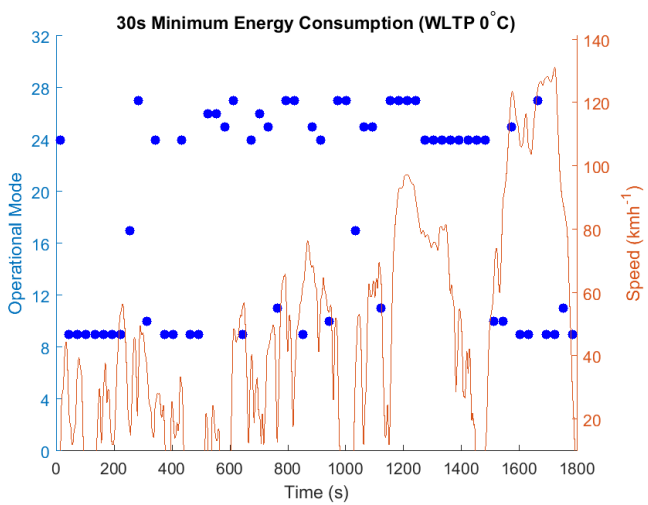

(c)

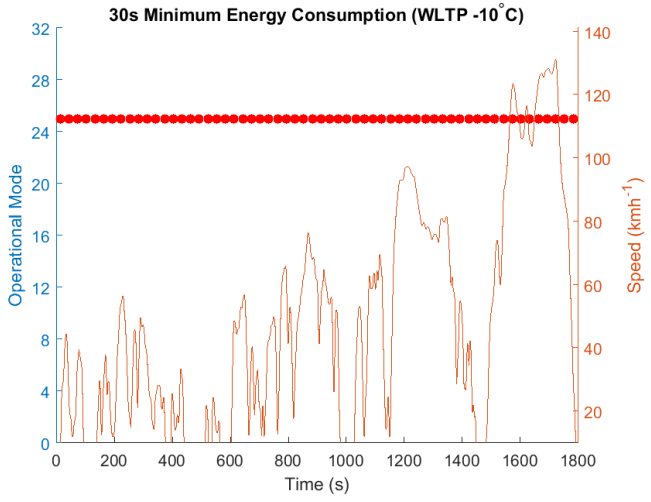

(b)

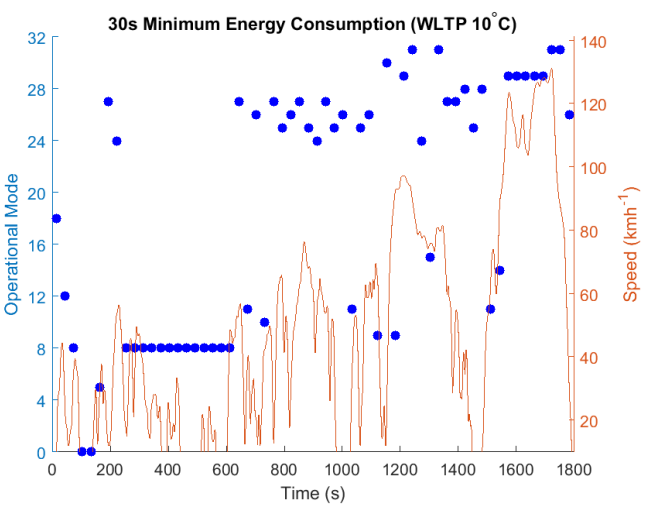

(d)

Figure 9. The best operational mode during $30 \mathrm{~s}$ intervals as a function of time is shown through the Warm up drive cycle over temperatures $-20^{\circ} \mathrm{C}(\mathbf{a}),-10^{\circ} \mathrm{C}(\mathbf{b}), 0^{\circ} \mathrm{C}(\mathbf{c})$ and $10{ }^{\circ} \mathrm{C}(\mathbf{d})$. Blue dots show the operational mode which used the least energy during that $30 \mathrm{~s}$ interval. This has been overlaid with the WLTP cycle. Red dots indicate when no operational mode met cabin target temperature, blue dots indicate multiple operational modes met cabin target temperature. 
In Figures $7 \mathrm{a}, 8 \mathrm{a}-\mathrm{c}$, and $9 \mathrm{a}, \mathrm{b}$ none of the operational modes reach the cabin target temperature hence the mode which reaches the highest cabin temperature is chosen; the cabin temperatures reached can be seen in Figure 10. In all but one case (Figure 8c) this was mode 25. However, when the cabin temperature is reached (Figures $7 \mathrm{~b}-\mathrm{d}, 9 \mathrm{c}, \mathrm{d}$ ) a variety of operational modes become available for comparison through the drive cycle. When this is the case, it becomes clear from the figures mentioned that the best performing operational mode is dependent on the demands given by the drive cycle. For the WarmUp cycle, shown in Figure 7 , it is evident from $0{ }^{\circ} \mathrm{C}$ and $10{ }^{\circ} \mathrm{C}$ that the best operational modes seem to change as the vehicle accelerates from the slow cruise to the fast cruise. Before this transition the best operational modes are mixed between modes 5, 8, 24, 25, and 27; however, shortly after the transition the best performing operational modes become dominated by a few higher modes, in the case of $10^{\circ} \mathrm{C}$ this is almost exclusively mode 31. It should also be noted that after the fast sections in Figure $7 \mathrm{c}, \mathrm{d}$ that the preferable modes begin to vary again and the mode number reduces. The same dynamics are not seen in the best performing operational mode at $-10^{\circ} \mathrm{C}$; this is likely because only a few operational modes were able to reach cabin temperature and therefore there is less choice available to minimise electrical energy consumption. It is noteworthy that the modes that did reach cabin target temperature seem limited to modes 29 and 31 . These differ in that 31 has all components connected to the heat pump, whereas 29 does not make use of the transmission. It is likely the transmission is not favoured in the early stages of the drive cycle because its inefficiency is too costly to the tractive power consumption while cold.

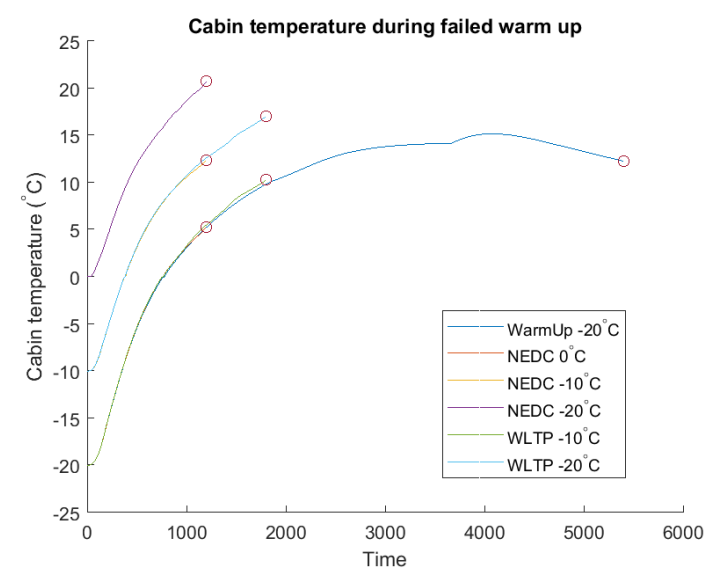

Figure 10. Here the cabin temperatures are shown for the best performing operational mode in scenarios where all modes failed to meet the target cabin temperature of $22^{\circ} \mathrm{C}$.

Similar trends can be seen in the NEDC and WLTP results. For NEDC at $10^{\circ} \mathrm{C}$, it can be noticed that mode 8 seems preferable during the low speed section of the cycle, while higher modes become popular during the later, faster stages. Mode 8 exclusively uses the thermal battery; whereas the higher modes make use of the motor, transmission and cabin exhaust recovery. Similar trends can be noted for WLTP at $0{ }^{\circ} \mathrm{C}$ and $10^{\circ} \mathrm{C}$.

To generalise these results, vehicle speed and operational mode number show some correlation. As the operational mode number increases more components become connected to the heat pump, until mode 31 is reached, when all components are connected. As the vehicle speed increases more waste heat is generated by the motor and transmission, and the battery benefits more from being heated. This is a plausible explanation for the trend seen in the data presented. Furthermore it is confirmation that there is not one operational mode which best suits all conditions. This means that some switching of operational modes should be used through the drive cycle as a way to minimise energy consumption. Further investigation into which components are most useful to a heat pump under various circumstances should be carried out. This would help to guide how switching between operational modes during a drive cycle might occur. 


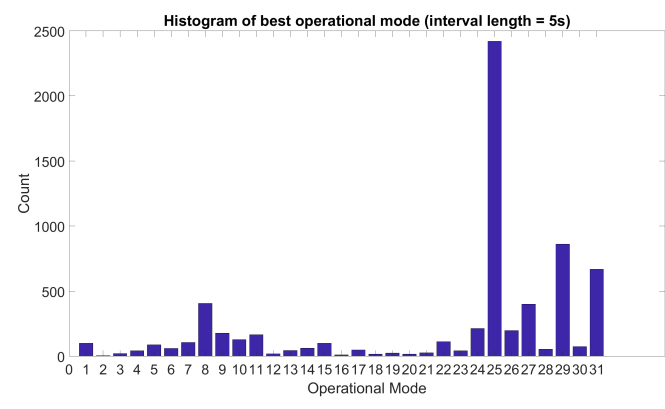

(a)

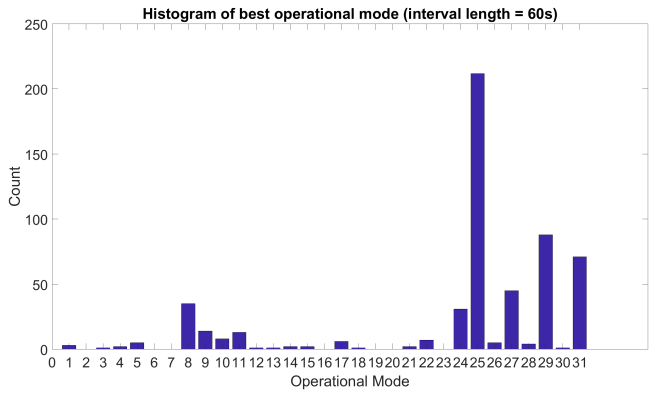

(c)

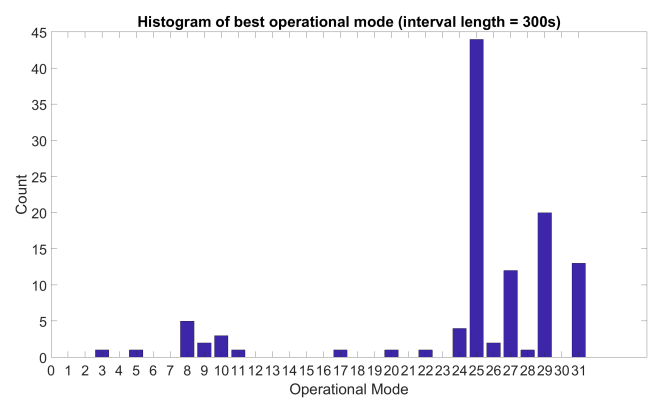

(e)

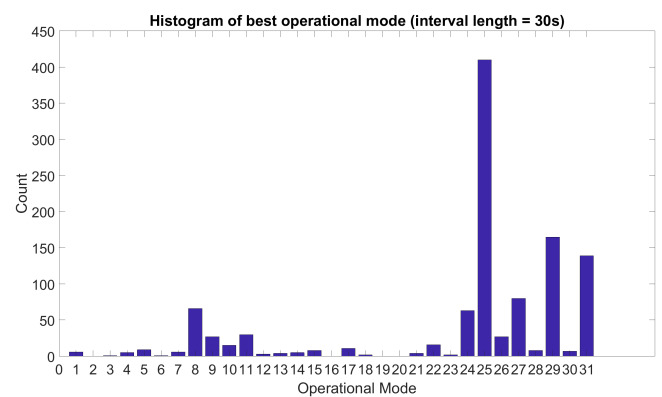

(b)

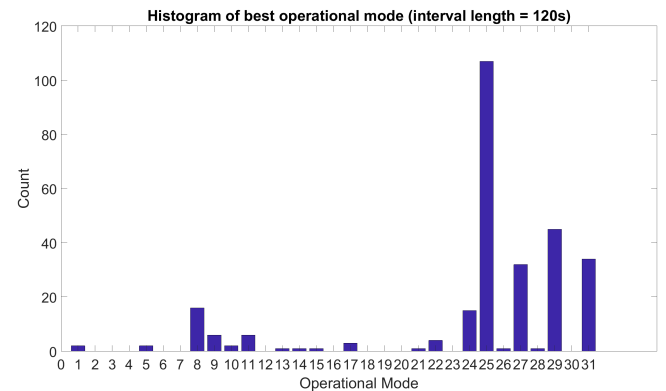

(d)

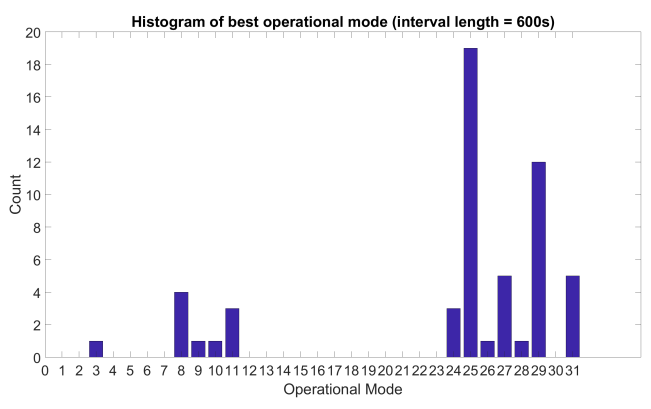

(f)

Figure 11. These histograms show how often each mode is selected during each of the different interval lengths. (a-f) show interval lengths 5, 30, 60, 120, 300, and 600 s respectively.

To make further comparisons on which operational modes generally perform well the histogram given in Figure 11 has been produced and the top 5 most commonly used modes have been extracted. The interval lengths $5 \mathrm{~s}, 30 \mathrm{~s}, 60 \mathrm{~s}, 120 \mathrm{~s}, 300 \mathrm{~s}$ and $600 \mathrm{~s}$ all have a common top 5 operational modes; $25,29,31,8$ and 27 (the order of top modes is not the same for all lengths of intervals). These modes are broken down into their composite contributors in Table 2 . These modes represent $70.8 \%, 70.8 \%$, $72.4 \%, 73.5 \%, 73.5 \%$ and $75.2 \%$ of the all modes shown in Figure 11 for interval lengths $5 \mathrm{~s}, 30 \mathrm{~s}$, $60 \mathrm{~s}, 120 \mathrm{~s}, 300 \mathrm{~s}$ and $600 \mathrm{~s}$ respectively. From Table 2 it is noteworthy that the top 5 operational modes all make use of the thermal battery. This provides justification for removing the thermal battery as an optional thermal contributor and implementing it as a permanent one. Removing a thermal contributor reduces computational effort and decreases the time it takes to find the optimum operational mode. Likewise, eliminating operational modes or contributors which are hardly used also reduces computational effort. This is an important consideration if a dynamic optimisation were to be performed. 
Table 2. Break down of the top 5 modes used when setting interval lengths of $5 \mathrm{~s}, 30 \mathrm{~s}, 60 \mathrm{~s}, 120 \mathrm{~s}, 300 \mathrm{~s}$ and $600 \mathrm{~s}$, broken down into composite thermal contributors.

\begin{tabular}{cccccc}
\hline \multirow{2}{*}{ Mode } & \multicolumn{5}{c}{ Components } \\
\cline { 2 - 6 } & Motor & Thermal Battery & Electric Battery & Transmission & Cabin Exhaust \\
\hline 25 & 1 & 1 & 0 & 0 & 1 \\
29 & 1 & 1 & 1 & 0 & 1 \\
31 & 1 & 1 & 1 & 1 & 1 \\
8 & 0 & 1 & 0 & 0 & 0 \\
27 & 1 & 1 & 0 & 1 & 1 \\
\hline
\end{tabular}

After the operational modes have been broken down into the constituent components, analysis of how often each component is used can be made; as seen in Figure 12, where the $30 \mathrm{~s}$ interval length data is presented as to be compatible with Figures 7-9. Figure 12a shows the proportion of instances each component appeared in the best performing operational mode across all drive cycles and temperatures.

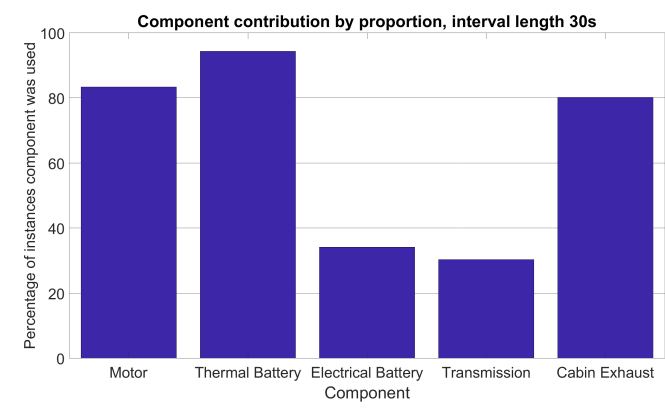

(a)

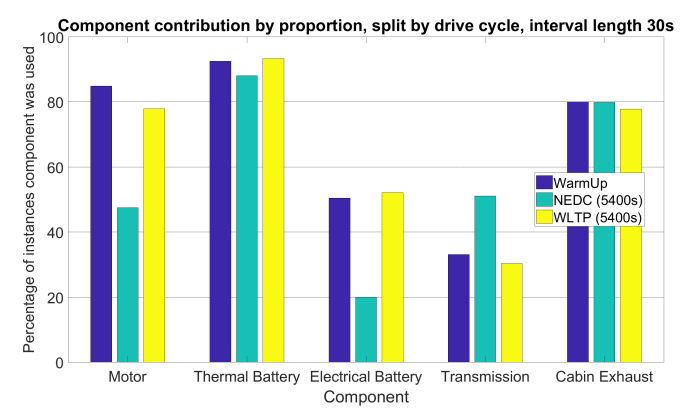

(c)

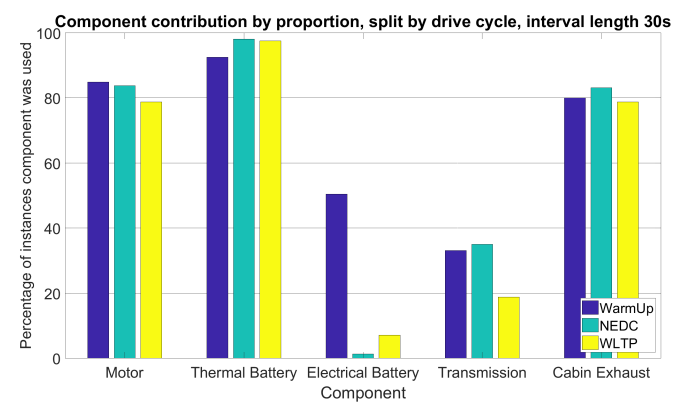

(b)

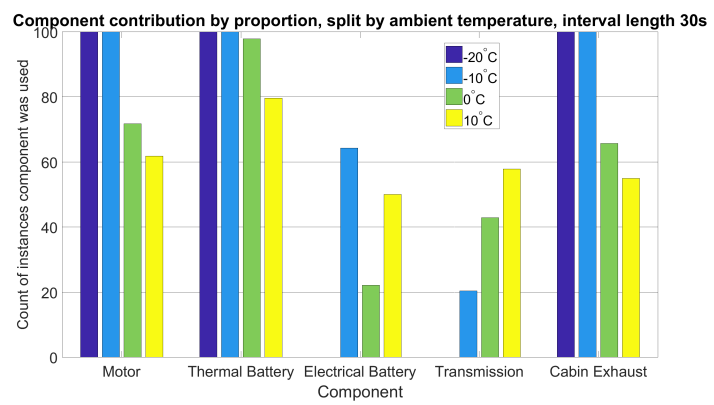

(d)

Figure 12. The percentage of instances the best performing operational modes made use of each component across all drive cycles and temperatures. (a) shows the contribution of each component over all scenarios, (b) shows the contribution of each component split over each of the drive cycles tested, (c) shows the contribution of each component split over each of the drive cycles tested (extended to $5400 \mathrm{~s}$ ), and (d) shows the contribution of each component split over the range of temperatures tested.

Figure 12a can also be used to assess the usefulness of each component when being used with a heat pump over all drive cycles and temperatures. It is apparent that the motor, thermal battery and cabin exhaust extraction are the most beneficial components when using a complex heat pump. The least beneficial of these components was used in $>80 \%$ of the best performing operational modes during all drive cycles and temperatures. This reflects the previous analysis made on Figure 11 and Table 2; where mode 25 was dominant and comprised of the motor, thermal battery and cabin exhaust. The thermal battery shows such dominance in its usage with the heat pump that it should 
possibly be excluded from the operational modes and permanently connected to the heat pump. It is expected that the motor and cabin exhaust recovery are also popular because these components have no trade off in efficiency increase or cabin temperature decrease. Conversely, when heat is extracted from the transmission its efficiency decreases and hence approximately of $70 \%$ the time (according to Figure 12a) it is not worth extracting this heat. Additionally, when the battery is heated it takes heating capacity away from the cabin; therefore, under most circumstances it is not preferable to sacrifice cabin temperature for battery efficiency gains. These two compromises have greater negative effects over shorter drive cycles compared to longer drive cycles. During longer cycles the cabin target temperature is reached early in the cycle and transmission has time to warm up, so these two components may be of greater importance. This is investigated by looking at the distribution of component contributions as a function of drive cycle and temperature.

Figure $12 \mathrm{~b}$ gives a break down of the proportion of instances each component appears in the best performing operational mode as a function of drive cycles. From these figures it can be seen that the motor, thermal battery and cabin exhaust are dominant. As postulated, the electric battery becomes more important as the length of the drive cycle increases, with the electric battery heating being most beneficial in WarmUp (5400 s), then WLTP (1800 s) and least beneficial in NEDC (1200 s). This implies that the electric battery should be heated when the cabin has reached temperature in order to benefit from efficiency gains. The transmission shows less importance compared to the motor, thermal battery and the cabin recovery. However, it is not clear that its use is correlated with the drive cycle chosen. It seems to be most useful on the NEDC cycle, which is the shortest and second most dynamic cycle; importance then seems to be dependant on the interval time used. Hence it is difficult to reach a meaningful conclusion regarding when to extract heat from a transmission according to the drive cycle used.

To confirm the hypothesis regarding heating the battery with the heat pump, the NEDC and WLTP drive cycles were repeated to match the length of the WarmUp cycle, and the method was repeated. Figure 12c shows proportion of time the components appear in the best performing mode when tested on these longer cycles. Here it can be seen that the battery appears in a higher proportion of the best performing operational modes compared to Figure $12 \mathrm{~b}$ during the NEDC and WLTP cycles. This confirms that duration of a drive cycle is the dependant variable which should be used to decide if the battery should be heated. Furthermore, the more aggressive WLTP drive cycles favours battery heating over NEDC. Since the WLTP cycle has a higher average speed $\left(46 \mathrm{kmh}^{-1}\right.$ compared to $33 \mathrm{kmh}^{-1}$ ) and efficiency of the battery becomes worse with increased speed due to $I^{2} R$ losses, this is a predictable outcome. This is further reflected by the tractive power consumption $(7.5 \mathrm{~kW}$ vs. $12.5 \mathrm{~kW}$ and $9.8 \mathrm{~kW}$ ) when comparing NEDC to WLTP and WarmUp respectively.

In addition to the conclusions drawn about the battery, it can be noted from the extended drive cycles that the preference towards the motor and thermal battery has decreased. It is likely that now the cycles are longer the cabin target temperature is reached sooner (relative to the length of the cycle) hence the extra heat from the motor and thermal battery is not needed. This would lead to these components appearing less in the best performing operational modes.

Figure 12d gives a break down of the proportion of times each component appears in the best performing operational mode as a function of ambient temperature. Here there is a clearer conclusion when looking at the dependency of transmission usage on ambient temperature; more benefit is received from the transmission as ambient temperature increases. This is likely because cold transmissions are inefficient and the efficiency trade off is not as valuable when the ambient temperature is very low. The electric battery also displays an interesting dependency on temperature, it appears as though heating the battery can be beneficial in colder and warmer conditions, but not necessarily between these two. Heating the battery at lower temperatures will see larger efficiency benefits, while heating the battery after the cabin warms up also gives efficiency benefits while not sacrificing cabin temp. The minimum at $0{ }^{\circ} \mathrm{C}$ can therefore be explained since the electric battery is not cold enough to get a large efficiency gain, and the cabin requires too much heat still to send any 
to the battery. Hence, deciding when the battery should be heated during a drive cycle becomes an important and interesting optimisation problem.

While the motor, thermal battery, and cabin exhaust still appear to be of high importance at lower temperatures, their importance seems to diminish as the temperature increases. The most probable explanation for this is that as ambient temperature increases, the proportion of time heating the cabin is reduced, which means less heating power is required. Since it takes energy to pump heat from these components they should be disconnected from the heat pump when less heat is needed.

\section{Discussion}

Here it has been shown that the management of a complex heat pump needs to be considered carefully to achieve the best performance over a range of conditions. Previous literature has explored the extraction of heat from the drive motors to benefit a heat pump; here it has been proven that this is correct under low temperature conditions. However as the ambient temperature gets higher it has been shown that the use of the motor for thermal support should be reduced. The use of a thermal battery with an automotive heat pump has previously not been explored in literature; here it has been comprehensively shown at low temperatures it is beneficial to use a device of this nature with a heat pump. Extracting heat from cabin exhaust is also beneficial to a complex heat pump, and follows the same trends with ambient as the motor and thermal battery.

Using the complex heat pump to heat the battery shows a benefit under specific conditions. It was seen in initial testing that the battery heating was most beneficial during the WarmUp cycle, which was the longest of the three cycles tested. The hypothesis proposed from this was that battery heating was more important during longer drive cycles. This was further confirmed when retesting was done with repeated NEDC and WLTP cycles to replicate the length of the WarmUp cycles. When these repeated cycles were used, heating the battery during WLTP resembled a similar importance to the WarmUp cycle. In the case of the NEDC cycle, battery heating was not used as frequently in the best performing operational modes when compared to both WLTP and WarmUp. This is likely because the NEDC has both a lower average speed $\left(33 \mathrm{kmh}^{-1} \mathrm{vs} .46 \mathrm{kmh}^{-1}\right.$ and $\left.50 \mathrm{kmh}^{-1}\right)$ and lower average tractive power consumption $(7.5 \mathrm{~kW}$ vs. $12.5 \mathrm{~kW}$ and $9.8 \mathrm{~kW})$ when compared to WLTP and WarmUp respectively. Since WLTP and WarmUp both have increased speed and power it follows that a warmer, more efficient battery becomes more important.

It was also shown that battery heating usage varies with temperature. From Figure $12 \mathrm{~d}$ it was seen that the battery heating was highly beneficial at $-10^{\circ} \mathrm{C}$ and $20^{\circ} \mathrm{C}$, slightly beneficial at $0{ }^{\circ} \mathrm{C}$ and unused at $-20{ }^{\circ} \mathrm{C}$. A possible explanation is the mix of cabin heating and battery efficiency; at $-20^{\circ} \mathrm{C}$ the cabin requires all heat from the heat pump and so the battery is neglected, whereas at $-10{ }^{\circ} \mathrm{C}$ the cabin can reach temperature while the battery is being heated and so it can be worth making the compromise for improved energy consumption. As the ambient temperature increases battery efficiency also increases which might explain why battery heating does not appear to be as useful at $0{ }^{\circ} \mathrm{C}$. Finally, at $10^{\circ} \mathrm{C}$ the cabin heating demand is significantly reduced and so there is more surplus heat which can be used for the battery. This is the proposed explanation for the results seen regarding the batteries relationship to ambient temperature. Further investigations should be undertaken to understand when the battery of an electric vehicle should be heated. This research should also extend to the battery's relationship with vehicle speed and drive cycle length.

Further thought should also be given to the use of transmission with a complex heat pump as a function of drive cycle, as no clear conclusion could be drawn from the analysis presented. It is clear however that the transmission becomes more beneficial to the complex heat pump as the ambient temperature increases.

It has also been shown that the frequency at which the best operational mode is evaluated has an effect on the range of operational modes that should be considered for use. It was seen that the top 5 best performing operational modes were common across all frequencies tested and this covered $>70 \%$ of all best performing modes, evidenced in Figure 11 . The conclusion to this is that while 
fast evaluations of the best operational mode increases the range of operational modes that might be used, for the most part the same modes appear to be the best to use regardless of switching frequency. Hence when a dynamic optimisation is carried out to find the best trajectory of operational modes to take during a drive cycle, the switching frequency should be considered carefully. Considering the characteristic time of the drive cycle for which the operational mode trajectory is being optimised in order to guide the choice of switching frequency might further improve energy consumption and thermal comfort.

\section{Conclusions}

A model has been generated which allows for multiple heat sources to be arbitrarily connected to a heat pump for an electric vehicle. This has allowed significant progress to be made in understanding how the best performance can be extracted from a complex heat pump in electric vehicles. It also provides guidance into which components are most important for heat extraction in a system designed for limited thermal contributors; specifically the motor, a thermal battery and cabin exhaust recovery are critical for the optimal performance of a heat pump. Further progress and estimations of potential energy savings will be achieved through dynamic optimisation of the operational mode through a drive cycle. While the current method has provided insight into the best operational modes to use, it is incomplete as the thermal and energetic history of each mode has been ignored when selecting that mode as best for a given interval.

From the above analysis it is apparent that a complex heat pump with multiple possible operational modes reduces total electrical energy consumption when operated over a range of temperatures. This is evidenced by the $14.8 \%$ average energy saving seen in Figure 6 . It has been shown that there the key components which can improve the performance of a heat pump are the motor, thermal battery and the cabin exhaust. These components have no temperature based efficiency trade off and so heat can be extracted from with little cost. These components were seen to be beneficial under a wide range of vehicle conditions. Heating the battery and extracting heat from the transmission can be beneficial under some circumstances. This should be investigated further to maximise the performance of an automotive heat pump. Furthermore, the evidence presented in Figures 7-9 suggests a greater reduction in total electrical energy consumption will come from dynamically selecting operation mode according to the state of the vehicle through the drive cycle.

To achieve this a dynamic optimisation should be carried out with the aim of finding the optimal operational mode trajectory for a range of scenarios. Furthermore the objective function should be considered carefully. Rather than solely focussing on the total electrical energy consumption while limiting available modes according to whether cabin target temperature was reached, as in Section 4, a multi-objective optimisation question should be considered. This would involve a weighted balance between total electrical energy consumption, a cabin comfort parameter and remaining range (distinguished from total electrical energy consumption due to its dependency on battery temperature). A multi-objective optimisation problem of this nature would address all of the issues with low temperature electric vehicle operation identified in Section 1.

Author Contributions: For research articles with several authors, a short paragraph specifying their individual contributions must be provided. The following statements should be used "Conceptualization, J.J.; Methodology, J.J.; Formal Analysis, J.J.; Investigation, J.J.; Resources, A.P. and Y.T.; Software, A.P.; Writing-Original Draft Preparation, J.J.; Writing-Review \& Editing, A.M.; Supervision, D.W. and S.R.; Project Administration, A.M.; Funding Acquisition, S.R.'Jaguar Land Rover', A.M. and D.W. 'EPSRC'.

Funding: This research was funded by EPSRC, grant reference number [EP/M507593/1], and Jaguar Land Rover. Conflicts of Interest: The authors declare no conflict of interest.

\section{References}

1. Roscher, M.A.; Leidholdt, W.; Trepte, J. High efficiency energy management in BEV applications. Int. J. Electr. Power Energy Syst. 2012, 37, 126-130. [CrossRef] 
2. How Do Extremely Cold Temperatures Affect the Range of an Electric Car? 2013. Available online: http: / / www.fleetcarma.com/electric-car-range-in-bitter-cold/ (accessed on 15 September 2016).

3. AAA Monthly Gas Price Report: March 2014 Trends and April Outlook. 2014. Available online: http: / / newsroom.aaa.com/2014/03/ (accessed on 15 September 2016).

4. Electric Vehicle Range Drops in Cold Weather, and Technological Solutions Are Years Away. 2013. Available online: https:/ / www.technologyreview.com/s/522496/electric-vehicles-out-in-the-cold/ (accessed on 15 September 2016).

5. Barnitt, R.A.; Brooker, A.D.; Ramroth, L.; Rugh, J.; Smith, K.A. Analysis of off-board powered thermal preconditioning in electric drive vehicles. In Proceedings of the 25th World Battery, Hybrid and Fuel Cell Electric Vehicle Symposium \& Exhibition, Shenzhen, China, 5-9 November 2010.

6. Kim, K.; Kim, S.; Kim, M. Experimental studies on the heating performance of the PTC heater and heat pump combined system in fuel cells and electric vehicles. Int. J. Automot. Technol. 2012, 13, 971-977. [CrossRef]

7. Meyer, N.; Whittal, I.; Christenson, M.; Loiselle-Lapointe, A. The impact of the driving cycle and climate on electrical consumption and range of fully electric passengers vehicles. In Proceedings of the EVS, Los Angeles, CA, USA, 6-9 May 2012.

8. Reyes, J.R.M.D.; Parsons, R.V.; Hoemsen, R. Winter happens: the effect of ambient temperature on the travel range of electric vehicles. IEEE 2015. [CrossRef]

9. Nagasubramanian, G. Electrical characteristics of $18650 \mathrm{Li}$-ion cells at low temperatures. J. Appl. Electrochem. 2001, 31, 99-104. [CrossRef]

10. Ji, Y.; Zhang, Y.; Wang, C.Y. Li-ion cell operation at low temperatures. J. Electrochem. Soc. 2013, 160, A636-A649. [CrossRef]

11. Fan, J. On the discharge capability and its limiting factors of commercial $18650 \mathrm{Li}$-ion cell at low temperatures. J. Power Sources 2003, 117, 170-178. [CrossRef]

12. Jaguemont, J.; Boulon, L.; Dubé, Y.; Poudrier, D. Low temperature discharge cycle tests for a lithium ion cell. In Proceedings of the 2014 IEEE Vehicle Power and Propulsion Conference (VPPC), Coimbra, Portugal, 27-30 October 2014.

13. Panosonic. Lithium Ion NCR18650; Panosonic: Kadoma, Japan, 2012.

14. Rui, X.; Jin, Y.; Feng, X.; Zhang, L.; Chen, C. A comparative study on the low-temperature performance of LiFePO 4/C and Li 3 V 2 (PO 4) 3/C cathodes for lithium-ion batteries. J. Power Sources 2011, 196, 2109-2114. [CrossRef]

15. Zheng, F.; Jiang, J.; Sun, B.; Zhang, W.; Pecht, M. Temperature dependent power capability estimation of lithium-ion batteries for hybrid electric vehicles. Energy 2016, 113, 64-75. [CrossRef]

16. Petzl, M.; Kasper, M.; Danzer, M.A. Lithium plating in a commercial lithium-ion battery-A low-temperature aging study. J. Power Sources 2015, 275, 799-807. [CrossRef]

17. Waldmann, T.; Wilka, M.; Kasper, M.; Fleischhammer, M.; Wohlfahrt-Mehrens, M. Temperature dependent ageing mechanisms in Lithium-ion batteries-A post-mortem study. J. Power Sources 2014, 262, 129-135. [CrossRef]

18. Jaguemont, J.; Boulon, L.; Dubé, Y. Characterization and modeling of a hybrid-electric-vehicle lithium-ion battery pack at low temperatures. IEEE Trans. Veh. Technol. 2016, 65, 1-14. [CrossRef]

19. Matthe, R.; Turner, L.; Mettlach, H. VOLTEC battery system for electric vehicle with extended range. SAE Int. J. Engines 2011, 4, 1944-1962. [CrossRef]

20. Hayes, J.G.; de Oliveira, R.P.R.; Vaughan, S.; Egan, M.G. Simplified electric vehicle power train models and range estimation. In Proceedings of the 2011 Vehicle Power and Propulsion Conference (VPPC), Chicago, IL, USA, 6-9 September 2011.

21. Saxena, S.; Le Floch, C.; MacDonald, J.; Moura, S. Quantifying EV battery end-of-life through analysis of travel needs with vehicle powertrain models. J. Power Sources 2015, 282, 265-276. [CrossRef]

22. Lindgren, J.; Lund, P.D. Effect of extreme temperatures on battery charging and performance of electric vehicles. J. Power Sources 2016, 328, 37-45. [CrossRef]

23. Broglia, L.; Autefage, G.; Ponchant, M. Impact of passenger thermal comfort and electric devices temperature on range: a system simulation approach. World Electri. Veh. J. 2012, 5, 1082-1089. [CrossRef]

24. Shin, Y.H.; Ahn, S.K.; Kim, S.C. Performance characteristics of PTC elements for an electric vehicle heating system. Energies 2016, 9, 813. [CrossRef] 
25. Torregrosa-Jaime, B.; Payá, J.; Corberan, J. Design of efficient air-conditioning systems for electric vehicles. SAE Int. J. Alter. Power 2013, 2, 291-303. [CrossRef]

26. Helms, H.; Pehnt, M.; Lambrecht, U.; Liebich, A. Electric vehicle and plug-in hybrid energy efficiency and life cycle emissions. In Proceedings of the 18th International Symposium Transport and Air Pollution, Zürich, Switzerland, 18-19 May 2010.

27. De Gennaro, M.; Paffumi, E.; Martini, G.; Manfredi, U.; Scholz, H.; Lacher, H.; Kuehnelt, H.; Simic, D. Experimental Investigation of the Energy Efficiency of an Electric Vehicle in Different Driving Conditions; Technical Report for SAE 2014 World Congress \& Exhibition; SAE International: Warrendale, PA, USA, 14 April 2014.

28. Leighton, D. Combined fluid loop thermal management for electric drive vehicle range improvement. SAE Internat. J. Passeng. Cars-Mech. Syst. 2015, 8. [CrossRef]

29. Ahn, J.H.; Kang, H.; Lee, H.S.; Jung, H.W.; Baek, C.; Kim, Y. Heating performance characteristics of a dual source heat pump using air and waste heat in electric vehicles. Appl. Energy 2014, 119, 1-9. [CrossRef]

30. Shahidinejad, S.; Bibeau, E.; Filizadeh, S. Design and Simulation of a Thermal Management System for Plug-in Electric Vehicles in Cold Climates; Technical Report for SAE 2012 World Congress \& Exhibition; SAE International: Warrendale, PA, USA, 16 April 2012.

31. Jha, K.K.; Badathala, R. Low Temperature Thermal Energy Storage (TES) System for Improving Automotive HVAC Effectiveness; Technical Report for SAE 2015 World Congress \& Exhibition; SAE International: Warrendale, PA, USA, 14 April 2015.

32. LaClair, T.J.; Gao, Z.; Abdelaziz, O.; Wang, M.; Wolfe, E.; Craig, T. Thermal Storage System for Electric Vehicle Cabin Heating-Component and System Analysis; Technical Report for SAE 2016 World Congress and Exhibition; SAE International: Warrendale, PA, USA, 5 April 2016.

33. Kaygusuz, K. Performance of solar-assisted heat-pump systems. Appl. Energy 1995, 51, 93-109. [CrossRef]

34. Jeffs, J.; McGordon, A.; Widanage, W.D.; Robinson, S.; Picarelli, A. Use of a thermal battery with a heat pump for low temperature electric vehicle operation. In Proceedings of the 2017 IEEE Vehicle Power and Propulsion Conference (VPPC), Belfort, France, 11-14 December 2017.

35. Peng, Q.; Du, Q. Progress in heat pump air conditioning systems for electric vehicles-A review. Energies 2016, 9, 240. [CrossRef]

36. Williamson, S.S. Electric drive train efficiency analysis based on varied energy storage system usage for plug-in hybrid electric vehicle applications. In Proceedings of the Power Electronics Specialists Conference, Orlando, FL, USA, 17-21 June 2007.

37. Hofman, T.; Dai, C. Energy efficiency analysis and comparison of transmission technologies for an electric vehicle. In Proceedings of the 2010 IEEE Vehicle Power and Propulsion Conference (VPPC), Lille, France, 1-3 September 2010.

38. Grady, M.L.; Jung, H.; chul Kim, Y.; Park, J.K.; Lee, B.C. Vehicle Cabin Air Quality with Fractional Air Recirculation; Technical Report for SAE 2013 World Congress \& Exhibition; SAE International: Warrendale, PA, USA, 8 April 2013.

39. Suck, G.; Spengler, C. Solutions for the Thermal Management of Electrically Driven Vehicles. ATZ Worldw. 2014, 116, 4-9. [CrossRef]

40. Zhu, T.; Min, H.; Yu, Y.; Zhao, Z.; Xu, T.; Chen, Y.; Li, X.; Zhang, C. An optimized energy management strategy for preheating vehicle-mounted li-ion batteries at subzero temperatures. Energies 2017, 10, 243. [CrossRef]

41. Taylor, R.A.; Chung, C.Y.; Morrison, K.; Hawkes, E.R. Analysis and testing of a portable thermal battery. J. Therm. Sci. Eng. Appl. 2014, 6, 031004. [CrossRef]

(C) 2018 by the authors. Licensee MDPI, Basel, Switzerland. This article is an open access article distributed under the terms and conditions of the Creative Commons Attribution (CC BY) license (http://creativecommons.org/licenses/by/4.0/). 